\title{
Evidence Synthesis Indicates Contentless Experiences in Meditation are Neither Truly Contentless Nor Identical
}

\author{
Toby J. Woods ${ }^{1}$, Jennifer M. Windt ${ }^{2}$, and Olivia Carter ${ }^{1}$ \\ ${ }^{1}$ Melbourne School of Psychological Sciences, The University of Melbourne, Melbourne, Australia \\ ${ }^{2}$ Department of Philosophy, Monash University, Melbourne, Australia
}

\begin{abstract}
Author Note
Toby J. Woods (1D https://orcid.org/0000-0002-0620-9994

Jennifer M. Windt (iD https://orcid.org/0000-0001-9862-8389

Olivia Carter (iD https://orcid.org/0000-0001-7708-6154
\end{abstract}

The present manuscript is a MindRxiv preprint. The manuscript has been submitted for publication and is currently under review. The final version is likely to differ from the current version in some respects. Toby Woods was supported in this work by an Australian Government Research Training Program scholarship, Jennifer Windt by an Australian Research Council Discovery Early Career Researcher Award (DE170101254) and a National Health and Medical Research Council Ideas Grant (APP2002454), and Olivia Carter by an Australian Research Council Future Fellowship (FT140100807).

Correspondence concerning this article should be addressed to:

Toby Woods (Toby.Woods@gmail.com) 


\begin{abstract}
Contentless experience involves an absence of mental content such as thoughts, perceptions, and mental images. In academic work it has been traditionally treated as including states like those aimed for in Shamatha, Transcendental, and Stillness Meditation. We have used evidence synthesis to select and review 135 expert texts from within the three traditions. In this paper we identify the features of contentless experience referred to in the expert texts and determine whether the experiences are the same or different across the practices with respect to each feature. We identify 65 features reported or implied in one or more practices, with most being reported or implied in all three. While there are broad similarities in the experiences across the traditions, we find that there are differences with respect to four features and possibly many others. The main difference identified is that Shamatha involves substantially greater attentional stability and vividness. Another key finding is that numerous forms of content are present in the experiences, including wakefulness, naturalness, calm, bliss/joy, and freedom. The findings indicate that meditation experiences described as contentless in the academic literature can in fact involve considerable variation, and that in many and perhaps most cases these experiences are not truly contentless. This challenges traditional understandings in academic research that in these so-called contentless experiences all content is absent, and that the experiences are therefore an identical state of pure consciousness or consciousness itself. Implications for neuroscientific and clinical studies and for basic understandings of the practices are discussed.
\end{abstract}

Keywords: pure consciousness, consciousness as such, minimal phenomenal experience, shamatha, transcendental meditation, stillness meditation 


\section{Evidence Synthesis Indicates Contentless Experiences in Meditation are Neither Truly Contentless Nor Identical}

The vast majority of scientific research on meditation has focused on brain activity or other physiological markers during meditation practice, or on the effects of practising (e.g., changes in brain activity, cognitive performance, or self-report on clinical scales) following a session. Very little work has scientifically examined meditators' subjective experience during meditation (Przyrembel and Singer 2018; Petitmengin et al. 2019). This represents a major gap, as subjective experience is at the heart of every practice and is essential for making sense of the other types of data (Schwitzgebel 2008; Thompson 2006/2008; Bitbol and Petitmengin 2013; Przyrembel and Singer 2018; Rigato et al., 2019).

In various forms of meditation an objective is "contentless" experience, in which mental content such as thoughts, sense-perceptions, body-perceptions, and mental images is absent (Stace 1960/1961; Forman 1990b, 1998; Shear 2006d). The meditation traditions view the experience as important, on the understanding that it leads to wide-ranging positive outcomes, including improvements to mental and physical health (e.g., Meares 1978/1986; Wallace 2006a; Pearson 2013). Academics have argued that, since the contents of consciousness are absent, the experience constitutes pure consciousness, or consciousness itself, and that it should therefore be prioritized as a research target in the field of consciousness studies (Stace 1960/1961; Forman 1990b; Shear 1990b; but see, e.g., Dainton 2000, 2002; Lancaster 2004, Studstill 2005; Gellman 2018). Recent work at the intersection of cognitive science and philosophy has given it that focus (Josipovic and Miskovic 2020; Millière et al. 2018; Metzinger 2020a; Millière 2020; Costines et al. 2021; Gamma and Metzinger 2021). In that research, contentless experience is referred to using terms such as pure consciousness, consciousness as such, and minimal phenomenal experience.

This paper examines contentless experience in three meditation practices: the Tibetan Buddhist Shamatha meditation presented by Alan Wallace (Wallace 2006a), Transcendental Meditation (“TM") (Maharishi Mahesh Yogi 1967/1974, 1963/2001), and Stillness Meditation (Meares 1967/1968; McKinnon 1983/2016). Wallace's Shamatha practice is one of many forms of shamatha meditation (Wallace 2011a, b), and shamatha is the type of Buddhist practice most closely associated with contentless state/s (Gimello 1978; Jones 1993; Wallace 2007b; Markovic and Thompson 2016). Wallace's practice and TM are frequently the subject of meditation research. The former has been central to a large-scale and long-running research program (see, e.g., Jacobs et al. 2011; Rosenberg et al. 2015; Zanesco et al. 2019), and up to the early 1990s TM was the most researched form of 
meditation (Shear 1990b; Lutz et al. 2007). Stillness Meditation was designed in the 1960s by the Australian psychiatrist Ainslie Meares (Meares 1967/1968). It has received minimal research attention (e.g., Seymour 1999; Hosemans 2017; Woods et al. 2020; Yerbury 2021). Unlike Shamatha and TM, it does not involve a meditation object. It therefore provides an interesting contrast with the other two practices.

In Shamatha, the meditator learns to pay attention to a meditation object, and then at a very advanced level relinquishes the object and moves into contentless experience (Wallace 2006a). The TM practitioner repeats a mantra silently in their mind, leading to contentless experience where awareness of the mantra falls away (Faber et al. 2017). Stillness Meditation involves doing nothing beyond maintaining the meditation posture (Meares 1978/1986; McKinnon 1983/2016). This includes giving up any effort to bring attention to an object or to otherwise maintain attention. In Stillness Meditation doing nothing is also said to lead to contentless experience.

For ease of reference, we will use the term "goal-state" to refer to the subjective experience of a state aimed for in a practice. ${ }^{1}$ We will use the term "interim-state" to mean an experience in the practice on the way to achieving the goal-state/s. In Woods et al. (2021) we describe the main features of the techniques and interim-states in Shamatha, TM and Stillness Meditation. The present paper is focused on the goal-states in those practices.

The goal-state is not necessarily regarded by the relevant meditation tradition as the deepest or most advanced state possible. For example, in the Tibetan Buddhist lineage known as Dzogchen, achieving the Shamatha goal-state is considered a prerequisite for the effective practise of insight meditation (Sanskrit: vipashyana) (Wallace 2006a, 2011b). Insight meditation is undertaken separately to Shamatha, and is seen as critical for achieving enlightenment (Wallace 2005, 2011b, 2012). Enlightenment, which is also termed pristine awareness, is viewed as much deeper than the Shamatha goal-state (Wallace 2011b, 2012).

One reason that contentless experience is of interest in cognitive science and philosophy is that it is so different from experiences in normal waking life. An enormous

Initial high-level reading indicated that Shamatha refers to a single goal-state: a specific subjective experience that arises at the most advanced stage of practice. TM is also frequently presented having a single goal-state (pure consciousness). The goal in Stillness Meditation is generally referred to as the experience of "stillness", and the initial high-level reading indicated that encompasses a range of states. In this paper we will use the terms "goal-state" (singular) and "goal-state/s" as appropriate in the context. For example, we will often use the term goal-state when discussing either Shamatha or TM texts that present the goal of the practice as a single subjective experience. Where we use the term goal-state/ $s$ with respect to a practice, it is to leave open the possibility that the practice aims for a range of subjective experiences, notwithstanding any claims to the contrary in the texts. In section 3.18 we seek to resolve this issue based on more detailed reading. 
amount of scientific research has been conducted with respect to mental content such as thoughts, perceptions and mental images that typifies ordinary waking experience. On the other hand, there has been hardly any scientific research on meditative experience where that content is reported to be absent (Vieten et al. 2018; Metzinger 2020a; Costines et al. 2021). It remains unclear precisely which content is absent in goal-states that are said to be contentless. Is it all content, or is there some content that is present? If there is content that is present, what could that be?

As indicated above, in the main strand of academic literature, goal-states like those in Shamatha, TM and Stillness Meditation have been described as contentless experience (Stace 1960/1961; Forman 1990b, 1998; Shear 2006d). Contentless experience has been commonly presented as lacking all content, and on this basis it has been argued or assumed that all instances of contentless experience are identical (Almond 1982; Bucknell 1989a, b; Bernhardt 1990; Forman 1990a; Shear 1990b). Based on these understandings, Shamatha, TM and Stillness Meditation each achieve an identical goal-state lacking all content despite the fact that they involve quite different techniques. Our analysis of expert texts from within the three traditions indicates that it is much quicker and easier to access the goal-states in TM and Stillness Meditation than the goal-state in Shamatha (Woods et al. 2021). This raises a further question, that overlaps with those above: Is it correct that the goal-states in the three practices are identical, or could it be that they differ in some way?

The present analysis addresses these questions. The aims are to: (a) identify the features of the goal-states referred to in expert texts from within the three traditions; and (b) determine whether the goal-states are the same or different across the practices with respect to each feature. To the best of our knowledge, this analysis is the first to identify features of the goal-states in the three practices based on expert texts selected and reviewed using a scientific method. It is also the first detailed comparison of the goal-states across the three practices.

\section{Method}

\subsection{Evidence synthesis}

The current paper, together with Woods et al. (2020), constitutes an evidence synthesis compliant with the ENTREQ reporting guidelines for qualitative evidence syntheses (Tong et al. 2012). Online Resource 1 lists the section/s that address each of the 21 items on the ENTREQ checklist. The four steps in the evidence synthesis process are summarized in Figures 1 and 2 (for a detailed description of the process, see Woods et al. 2020, pp.3-9 together with Online Resource 2 for the present paper). 


\section{The "extraction tables" for Shamatha, TM and Stillness Meditation referred to in}

step 3 are in total 194 pages and are supplementary material in Woods et al. (2020). In this

paper we will refer to the tables using the abbreviation SH, TM or SM followed by the relevant section number.

(a)

(b)

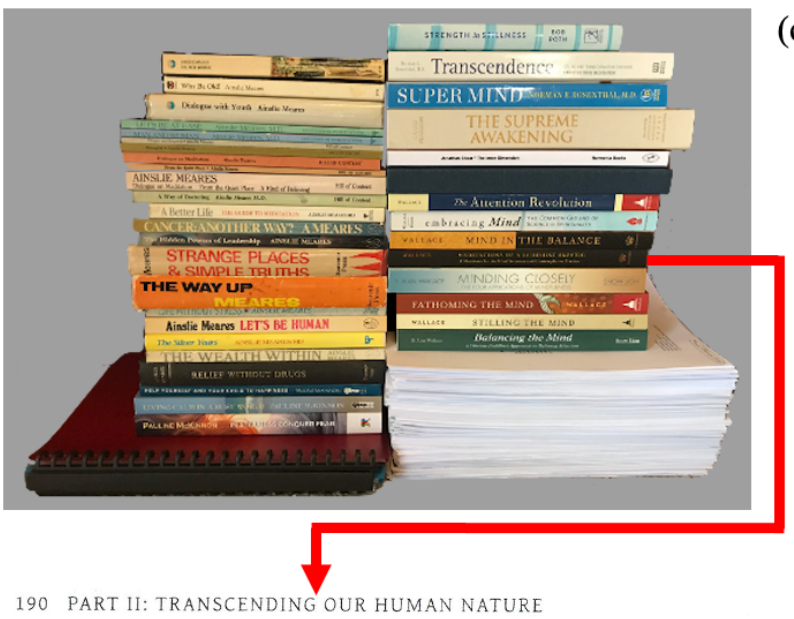

they eventually disappear by themselves, and consciousness rests in a spacious and loose state..$^{38} \mathrm{He}$ describes the culmination of this shamatha practice of observing the mind:

Consciousness comes to rest in its own state, mindfulness emerges, and because there is less clinging to experiences, consciousness settles into its own natural, unmodified state. In this way you come to a state of naturally settled mindfulness. That experience is soothing and gentle, with clear, limpid consciousness that is neither benefited nor harmed by thoughts; and you experience a remarkable sense of stillness without needing to modify, reject, or embrace anything. ${ }^{39}$

All subtle and coarse thoughts vanish;

ing disappears into the substrate consciousness; and all appearances of oneself, others, and objects disappear into the substrate. (c) 2.14.14 No thoughts

Wallace (2006a)

“... discursive thoughts become dormant ..."- p. 122

“... [D]ivest your consciousness of all ... thoughts ..." -p. 161

“... with consciousness disengaged from all discursive thought ..."-p. 161

“... your attention is ... withdrawn from ... discursive thoughts ..." - p. 161

Quoting Düdjom Lingpa: "Eventually all coarse and subtle thoughts will be calmed ... You will become still in an unfluctuating state ..." - p. 161

Wallace (2011b)

"When the mind is quiescent - no turbulent thoughts or emotions arising - it is relaxed, still, luminous, and free from effort. That is shamatha." - p. 62

“... [Y] ou have withdrawn limpid clear consciousness ... away from internal chitchat ..."- p. 97

“... coarse and subtle thoughts dissolve ..." - p. 119

“... an equipoise wherein coarse and even subtle thoughts have vanished." - p. 170

“... [W] hen you've achieved shamatha, roving thoughts have all dissolved.”-p. 176

Wallace $(2009 / 2014)$

“... discursive thoughts ... gradually dissolve into the luminous vacuity of the mind." - p. 80

Wallace $(2012 / 2014)$

Wallace and Hodel (2008)

"All subtle and coarse thoughts vanish ..."- p. 190

"... all involuntary, discursive thoughts are pacified." -p. 188

Wallace (2007b)

"All that remains is a vacuous space of awareness, devoid of thoughts ..." - p. 92

Wallace $(1998 / 2005)$
In the section on Tsongkhapa's vision/understanding: "... with consciousness disengaged from all discursive thought ..."-p. 92

Fig. 1 Representation of steps 1 to 3 in the evidence synthesis process. The first step was to select for each practice samples of publications by expert/s with outstanding qualifications. Alan Wallace was selected as the expert for Shamatha; Craig Pearson, Norman Rosenthal, Bob Roth, Jonathan Shear, and Fred Travis as the experts for TM; and Ainslie Meares and Pauline McKinnon as the experts for Stillness Meditation. Samples of their publications were selected that revealed their understandings of the meditation techniques and experiences. For Pearson, Rosenthal, and Roth, the sample comprised recent major works that appear to present their understandings in a consolidated form. For the other five experts it comprised publications selected by applying eligibility criteria to their full output. For the eight experts combined, 135 publications were selected (panel a). The second step was to review the selected publications and extract (i.e., copy) information about the techniques and experiences. As an example, panel (b) is an excerpt from one of the Shamatha texts (Wallace 2012/2014, p.190). The highlighted statement, "All subtle and coarse thoughts vanish", describes a feature of the Shamatha goal-state ("No thoughts") and was therefore extracted. The third step was to place each extracted passage in an extraction table for the relevant practice and code it as indicating the relevant feature. To illustrate this, panel (c) is a simplified excerpt from the Shamatha extraction table. This excerpt relates to the "No thoughts" feature of the goal-state (see green highlighting). In this example, the extracted statement highlighted in yellow is coded "No thoughts" by placing it in this section of the Shamatha table. As can be seen, this section of the table also includes the other extracted passages that have been coded "No thoughts". 


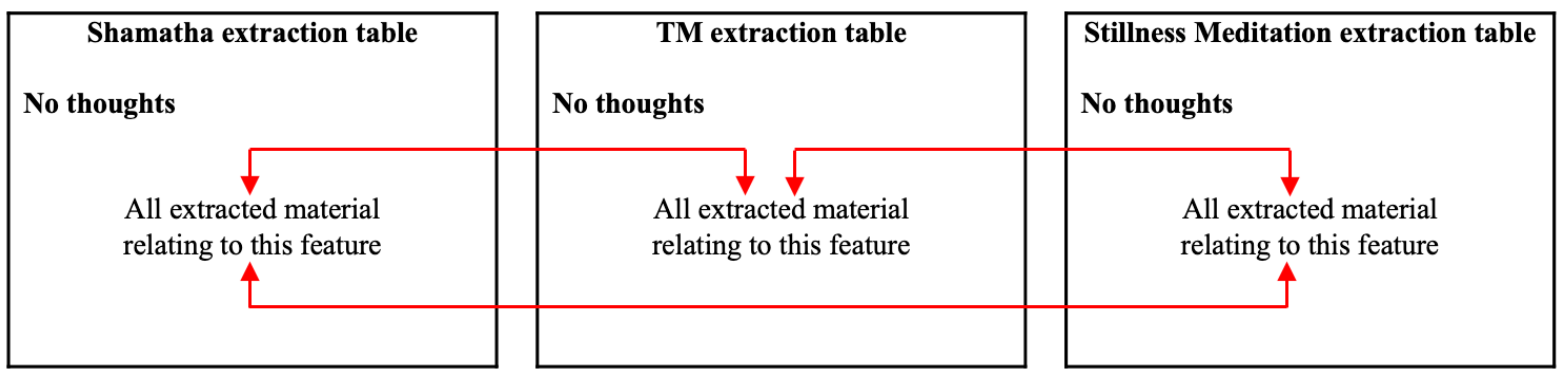

Fig. 2 Representation of step 4 in the evidence synthesis process. In this step we assessed whether the goalstates are the same (i.e., identical) or different across the practices with respect to each feature. This involved systematically comparing the extracted passages for each feature of the goal-states across the three practices. In the example here, the arrows depict the cross-practice comparison of the extracted material for the feature "No thoughts". The assessment "Unclear" (as opposed to "Same" or "Different") was made if: (a) a feature was not described with sufficient precision to reach a finding of sameness or difference; or (b) the feature was reported/implied in one practice but not addressed in another. Stillness, naturalness, and relaxation are examples of features meeting condition (a). Each is reported/implied in all three traditions, but it was not possible to work out whether the precise nature and level/degree was the same across the practices

\subsection{Treatment of inconsistent descriptions}

For some features of the goal-states, descriptions are inconsistent across experts in the relevant practice or within the texts of an individual expert. In section 3 we focus on the majority, or more widespread, descriptions, but also note the minority views.

One minority understanding advanced by Shear is that the TM goal-state lacks all or virtually all forms of content other than being conscious and awake. ${ }^{2}$ Other TM experts present the goal-state as involving numerous types of content in addition to being conscious and awake, and Shear also does this in other passages. As Shear's minority understanding is relevant to almost all the features of the goal-states, we will not repeat it for each of those features in section 3. Our assessments of whether the features are the same or different across the practices will be based on the majority descriptions. In the ground-states section (section 3.14) we will explain a possible way to reconcile Shear's minority understanding with the more widespread reports.

\subsection{Sources outside the extraction tables}

Our findings in section 3 are derived from the expert passages in the extraction tables. In a few places we also refer to passages and publications outside the tables in order to provide important context and facilitate understanding. Most sources outside the tables are easily identifiable in that they are not authored by one of the eight experts selected for the

2 Shear (1995/1997b, p.373) states that the TM goal-state involves the minimal content possible for a conscious experience. He says that it lacks not only content such as thoughts, perceptions, and images, but all abstract content too (TM2.7.15; Shear 1990a, p.396). He uses bliss as an example of abstract content, and implies that unboundedness is a further example (Shear 1990a, pp.396,398). He indicates that the meditator can report that they were conscious and awake, but can say almost nothing more (TM2.7.2). 
evidence synthesis. The remaining sources outside the tables are passages by the experts that were not extracted in the tables. To distinguish those sources we have marked them with an asterisk.

\section{Results}

For clarity, we have divided the goal-state features into 18 groups based on experiential or conceptual similarities or linkages (see further Online Resource 2).

\subsection{Group 1 - conscious, awake, wakefulness}

In each practice the meditator is said to be conscious and awake during the goalstate/s. ${ }^{3}$ The experts indicate that there is a heightened level of wakefulness. For example, Wallace describes the Shamatha meditator as highly alert, and vividly or luminously awake (Wallace 2011a, p.109, 2012/2014, p.199, 2009/2014, p.92). Pearson (2013) refers to the mind being "awake to its depth" in TM (p.45), and quotes a meditator saying "I have never been so clearly and entirely and fully awake" (p.53). Meares (1967/1968, p.59) describes the Stillness Meditation practitioner as "fully awake". 4 It is not clear whether the heightened levels of wakefulness referred to in each practice are identical.

Table 1 Group 1 - Summary of Findings

\begin{tabular}{|c|c|c|c|}
\hline Feature of the goal-state/s & $\begin{array}{l}\text { Extraction table } \\
\text { section/s }\end{array}$ & Practices reported/implied in & $\begin{array}{l}\text { Are the goal-states the same or } \\
\text { different across the three practices } \\
\text { with respect to this feature? }\end{array}$ \\
\hline
\end{tabular}

\begin{tabular}{|c|c|c|c|}
\hline $\begin{array}{l}\text { Conscious (as opposed } \\
\text { to not conscious) }\end{array}$ & $\begin{array}{l}\text { SH } 2.14 .2-2.14 .3 \\
\text { TM 2.7.3-2.7.4 } \\
\text { SM 2.3.2 }\end{array}$ & All three practices & Same \\
\hline $\begin{array}{l}\text { Awake (as opposed } \\
\text { to not awake) }\end{array}$ & $\begin{array}{l}\text { SH 2.14.4 } \\
\text { TM 2.7.5 } \\
\text { SM 2.3.3 }\end{array}$ & All three practices & Same \\
\hline $\begin{array}{l}\text { Heightened level of } \\
\text { wakefulness }\end{array}$ & As for row above & All three practices & Unclear \\
\hline
\end{tabular}

3 Rosenthal $(2016 / 2017$, p.36) notes that: "[S]ome people report going into a state of awareness where awareness of any sort disappears - until consciousness returns - when, lo and behold! twenty minutes have passed". On its face, that suggests that it is possible for there to be a loss of consciousness in the TM goal-state/s. The TM accounts as a whole, however, are overwhelmingly weighted towards the understanding that in the goal-states the meditator is conscious. On that view, the experience referred to by Rosenthal should not be regarded as a goal-state.

$4 \quad$ In places Meares also says that the practitioner is not "fully awake" (Meares 1967b, p.45, 1987/1991, p.127). The point he appears to be making there is that the meditator is having a very different kind of wakeful experience to the type they have in normal waking life. As an example, in the goal-states the meditator has no or virtually no awareness of what is going on around them. 


\subsection{Group 2 - emptiness/nothingness}

In all three practices, the basic understanding is that the goal-states involve no thoughts, images, memories, or feelings. ${ }^{5}$ In each practice, it appears that sense and body perceptions fade gradually as the meditator moves towards the goal-state/s. The Shamatha and TM goal-states are said to involve a complete absence of perceptions. The Stillness Meditation goal-states are said to involve a complete absence of perceptions, or perceptions that are only very dull.

Very dull perceptions in Stillness Meditation means sense or body impressions that are so vague and distant as to not convey any meaning for the meditator. McKinnon (2011, p.199) gives the example of hearing construction works undertaken outside the meditation room. To begin with, the noises are vividly perceived, but, as the meditation proceeds, they become vague and distant (Meares 1967/1968, p.83, 1978/1986; McKinnon 2011, pp.69,199, 1983/2016, pp.221,227). By that point they are simply sounds without meaning: They are not recognized as stemming from the construction site, and they do not disturb the meditative experience. Eventually they may fade from consciousness altogether.

In all three practices, it appears that the meditator may be brought out of the goalstate/s by particularly salient stimuli. For example, if they set an alarm-clock to cue the end of a session, it seems that they will perceive the alarm (Meares 1971a, p.676, 1973a, p.734; Wallace 2006a, p.162; Roth 2018, p.65).

Wallace (2018) speculates that in the Shamatha goal-state the meditator may be aware of the rhythm of their breathing. He distinguishes the rhythm of breathing from "tactile sensations" (p.11), which he says the meditator will not be aware of. Wallace only makes the comment about rhythm of breathing in one publication. The comment is speculative, because he bases it on reports of what he regards as a similar state in lucid dreamless sleep, as opposed to meditation. ${ }^{6}$ In the TM and Stillness Meditation goal-states the meditator is not aware of their breathing (Meares 1978/1986, p.15; Shear 2014b, p.211).

As referred to above, in all three practices the experts repeatedly state that there are no feelings in the goal-states. In other places, however, they identify features of the goal-

\footnotetext{
5 Rosenthal is an exception among the TM experts, in that some of his descriptions do not fit neatly with this understanding. For example, in some of his case studies, the meditators have ongoing awareness of their surrounding environment, or inner experiences of colours and lights (TM2.7.18, 2.7.48). He treats some of these cases as the TM goal-state/s, and in other cases he does not specify whether they are the goal-state/s or interim-states. Pearson, Shear and Travis more clearly express the basic understanding that the TM goal-state/s involve no sense-perceptions or images. Based on their approach, the examples given by Rosenthal would be classed as interim, rather than goal, states.

6 During a lucid experience of dreamless sleep, the person sleeping is aware of their state of consciousness (Thompson 2015; Windt et al. 2016).
} 
states that could be construed as feelings. The most obvious examples are the experiences of bliss, goodness, calm, ease and peacefulness. In one publication Wallace indicates that loving-kindness is a feature of the Shamatha goal-state, but in a later text he states that it is not (Wallace 2001a, pp.212-213,217, 2011a, pp.137,231-232).

When the experts say that there are no feelings, it appears that what they actually have in mind is particular feelings that are experienced in daily life. For example, they never refer to negative feelings as being part of the goal-states, which suggests that they understand those feelings to be absent. They may also have in mind certain neutral and positive feelings, such as any that are incompatible with other features of the goal-states. The experts implicitly distinguish between the relevant feelings experienced in daily life, and other types of feelings such as bliss, goodness, calm, ease, and peacefulness. The meditator moves beyond feelings of the first type, whereas feelings of the second type are generally presented as innate aspects of the meditator's mind or being that are discovered as part of the practices.

In the TM goal-state/s the meditator is no longer aware of the mantra. Shamatha is somewhat similar, in that as the meditator enters the goal-state they release the meditation object. That means that they are no longer mindful of the object: They cease attending to it. ${ }^{7}$ In Stillness Meditation there is no object at any point in the practice.

On the basis of the absence, or virtual absence, of various types of content, experts in all three practices note that there is little or no mental activity, and refer to the states as empty, or as involving nothing or an experience of nothingness. Wallace makes clear that the terms empty and emptiness in this context have a different meaning to their more common usage in Buddhist discourse (Wallace 2006a, pp.146,148, 2011b, p.175). Ordinarily emptiness refers to "[t]he absence of inherent existence of all phenomena" (Wallace 2011b, p. $\left.184^{*}\right)$, whereas here it simply describes the absence of the various types of content. ${ }^{8}$

Experts in the three practices use a number of terms to communicate the second type of emptiness. In TM, the goal-state is said to have no objects or qualities. TM and Shamatha refer to the goal-states as contentless and devoid of concepts. In Shamatha, nonconceptuality - meaning the absence of concepts - is presented as one of the fundamental features of the goal-state. Shamatha describes the emptiness as a vacuity or vacuum, and it

7 Wallace focuses on three types of Shamatha practice (see Woods et al. Submitted). In one of them, awareness of awareness, the meditation object is awareness itself. For this practice, the release of the meditation object appears to be very subtle (SH1.14.4). In the goal-state the meditator is still said to attend to awareness, but not as an object.

8 In the Dzogchen lineage, from which Wallace draws many of his understandings, insight (Sanskrit: vipashyana) practices (as opposed to shamatha) are generally considered necessary to realize the first type of emptiness (Wallace $2011 \mathrm{~b}$, pp.ix, $63^{*}$ ). 
refers to the absent content as dormant, in that it returns as the meditator emerges from the experience.

A closely related feature identified in Shamatha is the absence of grasping with respect to the absent content. TM and Stillness Meditation tend not to use the term grasping, but the emptiness of the goal-states implies that meditators in those practices have in some sense let go of the relevant content.

For the remainder of this paper we will use the term "everyday content" to describe the content that is absent, or virtually absent, from the goal-states. This is not a technical term, and we introduce it simply to provide a notation for that content. The word everyday signifies that the content is generally present in everyday waking life. The full term, everyday content, does not cover all of the content that is or may be present in everyday life. As a simple example, it does not include the sense of being conscious or awake, which remains present in the goal-states.

In each of the three traditions there is a clarification that the emptiness is not flat or barren, and that there is instead a depth or fullness to it. Referring to the empty "space of the mind" experienced in the Shamatha goal-state, Wallace (2011a, p.215) comments, "This space is not an empty nothingness - it's not flat empty". He then refers to the paradox that “emptiness is full” (p.215). Pearson (2013, p.444) says that the TM goal-state/s may be initially experienced as "flat", but that with practice the meditator may encounter "the internal, unmanifest reverberations, the inner dynamics of consciousness". He describes what is experienced in the latter case as "infinitely silent and infinitely dynamic, both together" (p.444). McKinnon (2011, pp.101-102) quotes a Stillness Meditation practitioner who refers to a "nothingness", but who then adds "yet it felt like everything". Meares (1976/1984, p.35) says that there is a depth to what is experienced, distinguishing it from oblivion (see sections 3.15 and 3.18 for further discussion concerning depth).

Table 2 Group 2 - Summary of Findings

\begin{tabular}{|c|c|c|c|}
\hline Feature of the goal-state/s & $\begin{array}{l}\text { Extraction table } \\
\text { section/s }\end{array}$ & Practices reported/implied in & $\begin{array}{l}\text { Are the goal-states the same or } \\
\text { different across the three practices } \\
\text { with respect to this feature? }\end{array}$ \\
\hline
\end{tabular}

\begin{tabular}{|c|c|c|c|}
\hline No thoughts & $\begin{array}{l}\text { SH } 2.14 .14 \\
\text { TM 2.7.16 } \\
\text { SM 2.3.11 }\end{array}$ & All three practices & Same \\
\hline No concepts & $\begin{array}{l}\text { SH } 2.14 .13 \\
\text { TM 2.7.14-2.7.15 } \\
\text { SM 2.3.10 }\end{array}$ & All three practices & Same \\
\hline
\end{tabular}


No sense or

body perceptions

Very dull sense or

body perceptions

No images

No memories

No feelings of

certain types

Loving-kindness

No awareness of

meditation object

(e.g., mantra or breath)

Little or no

mental activity

Emptiness/nothingness

Emptiness/nothingness

is not flat/barren, but has

a fullness/depth

No grasping with respect

to the everyday content
SH 2.14.16

TM 2.7.18-2.7.19

SM 2.3.13

SM 2.3.13

SH 2.14.17

TM 2.7.20

SM 2.3.14

SH 2.14.18

TM 2.7.21

SM 2.3.15

SH 2.14.15

TM 2.7.17

SM 2.3.12

SH 2.14.23

SH 2.14.24

TM 2.7.28

SM 1.8, 2.3.22

SH 2.14.13

TM 2.7.14-2.7.15

SM 2.3.10

As for row above

SH 2.14.21

TM 2.7.9

SM 2.3.7

SH 2.14.20

TM 2.7.14-2.7.15

SM 2.3.10
All three practices - only deeper

Same

goal-states in Stillness Meditation

Stillness Meditation only shallower goal-states ${ }^{\mathrm{a}}$

Different - not part of Shamatha or TM

All three practices

Same

All three practices

Same

All three practices

Unclear

Shamatha - reported in one

Unclear publication, ruled out in another

All three practices

Same

All three practices

Unclear

All three practices

Unclear

All three practices

Unclear

All three practices

Note. No awareness of breathing is covered by the body-perceptions and meditation object features. The table does not take into account Wallace's suggestion that non-tactile awareness of the rhythm of breathing may be a

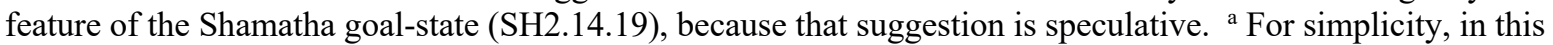
paper we will refer to the Stillness Meditation goal-states that involve very dull perceptions as "shallower" than those that involve none. Note, however, that it appears that the Stillness Meditation goal-states can deepen on a range of dimensions other than loss of perceptions. It therefore seems possible that certain goal-states with very dull perceptions may be deeper on particular dimensions than some goal-states that involve none.

\subsection{Group 3 - nonduality and recognition in retrospect}

Each of the practices identifies the absence of subject-object duality as a feature of the goal-states. In the Shamatha context, Wallace indicates that the dichotomy between the meditator and objects of experience is constructed by concepts (Wallace 2010, p.50), such as "'I' and 'not I"” (Wallace 2009/2014, p.94). Since there are no concepts in the goal-state, 
there is no subject/object dichotomy. Wallace (2010) says that, "[T]here is no longer a sense of the meditator" (p.50), and that what is left is "just the experience" (p.49).

The TM texts refer to the subject/object or "I ... it" (Shear 1990b, p.102) structure collapsing due to the absence of objects such as thoughts, perceptions, and the mantra. Pearson (2013, p.47) says that the subject, consciousness, "becomes its own object of experience", so that "the subject is the object". Shear (1990b, p.102) says that "the subject finds himself ... alone ... simply self conscious, without any object of awareness".

In Stillness Meditation, the absence of subject/object duality is described with reference to the relaxation that develops in the practice (Meares 1978/1986, pp.19-20,24-25). In the early stages of a meditation session, the individual has a sense of themselves, as subject, feeling the relaxation of the body, one of the objects of experience. As the session progresses, the relaxation deepens and becomes more prominent, extending beyond the body and permeating the meditator's whole being. The meditator - or equivalently, the subject/being - is then said to participate in the experience, rather than standing apart from it: "The separate entities cease to be separate" (Meares 1978/1986, p.20).

While the absence of subject-object duality is described in different terms in the three traditions, it could still be identical across the practices. The Shamatha and TM descriptions focus on the absence of everyday content (including concepts), and the absence of that content is also a feature in Stillness Meditation. The Stillness Meditation description emphasizes the absorptive nature of the relaxation. Shamatha and TM also involve deep relaxation, although it is not necessarily absorptive in the same way as in Stillness Meditation. It could be that the nonduality in the three practices comes about in different ways, but that the experience of it in the goal-states is still the same.

A separate but closely related feature concerns the point at which the goal-state experience is recognized. The TM and Stillness Meditation experts expressly state that the meditator only becomes aware that they have experienced the goal-states once they emerge from them. Wallace does not explicitly make this point for Shamatha, but it is implied by the fact that the Shamatha goal-state involves no introspection, thought or conceptualization. TM and Stillness Meditation experts elaborate on the point by noting that if the meditator is examining their state of mind, or has a thought such as "My mind is still", they are not experiencing the goal-state at that moment. Experts in all three traditions indicate that once the meditator emerges from the goal-state/s they are able to remember the experience. 
Table 3 Group 3 - Summary of Findings

\begin{tabular}{|c|c|c|c|}
\hline Feature of the goal-state/s & $\begin{array}{l}\text { Extraction table } \\
\text { section } / \mathrm{s}\end{array}$ & Practices reported/implied in & $\begin{array}{l}\text { Are the goal-states the same or } \\
\text { different across the three practices } \\
\text { with respect to this feature? }\end{array}$ \\
\hline $\begin{array}{l}\text { Absence of subject-object } \\
\text { duality }\end{array}$ & $\begin{array}{l}\text { SH } 1.17,2.14 .5 \\
\text { TM 2.7.6 } \\
\text { SM 2.3.4 }\end{array}$ & All three practices & Unclear \\
\hline $\begin{array}{l}\text { Only recognize the } \\
\text { experience upon emerging } \\
\text { from it }\end{array}$ & $\begin{array}{l}\text { SH } 2.14 .1 \\
\text { TM 2.7.1 } \\
\text { SM 2.3.1 }\end{array}$ & All three practices & Same \\
\hline
\end{tabular}

\subsection{Group 4 - stillness, silence, simplicity, naturalness}

In each practice, the goal-state/s are said to involve an experience of stillness, silence, simplicity, and naturalness. The experts often allow those terms to speak for themselves, rather than elaborating as to their meaning. The passages that do elaborate with respect to the term stillness suggest that it usually reflects the absence of disturbances such as thoughts, perceptions, and negative feelings. The terms silence and quietness reflect at least the absence of thoughts and sounds. The experts also leave scope for them to be interpreted as extending to the absence of other disturbances such as negative feelings. The feature silence/quietness is explored in more detail in Woods et al. (2020).

Table 4 Group 4 - Summary of Findings

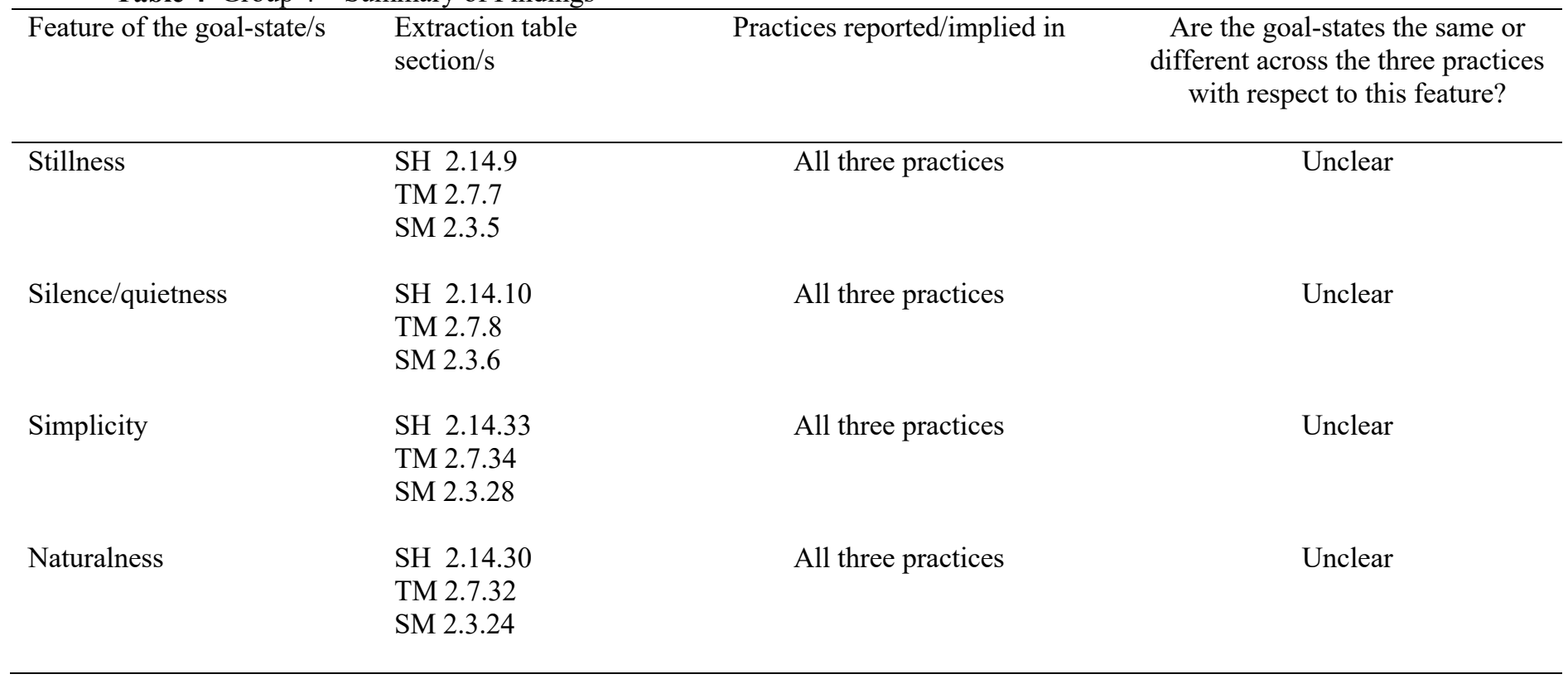

\subsection{Group 5 - calm, relaxation, rest}

Calm, ease and peacefulness are described as features of the goal-states, again reflecting that the mind is no longer disturbed by thoughts, perceptions, negative feelings, and so on. The meditator is relaxed, and experiences mental rest. Any earlier sense of 
discomfort from the posture or any other source is lost. In TM and Stillness Meditation there are explicit statements or reports that there is no sense of anxiety (Meares 1978/1986, pp.26,151,160; McKinnon 2011, p.84; Rosenthal 2011/2012, p.39; Roth 2018, pp.66-67).

Wallace does not expressly make that point for Shamatha, but it seems implied by his descriptions of the calm, ease and peacefulness.

Table 5 Group 5 - Summary of Findings

\begin{tabular}{|c|c|c|c|}
\hline Feature of the goal-state/s & $\begin{array}{l}\text { Extraction table } \\
\text { section/s }\end{array}$ & Practices reported/implied in & $\begin{array}{l}\text { Are the goal-states the same or } \\
\text { different across the three practices } \\
\text { with respect to this feature? }\end{array}$ \\
\hline $\begin{array}{l}\text { Calm, ease, peacefulness, } \\
\text { absence of disturbance }\end{array}$ & $\begin{array}{l}\text { SH } 2.14 .22 \\
\text { TM 2.7.24 } \\
\text { SM 2.3.18 }\end{array}$ & All three practices & Unclear \\
\hline Relaxation & $\begin{array}{l}\text { SH 2.14.11 } \\
\text { TM 2.7.12 } \\
\text { SM 2.3.8 }\end{array}$ & All three practices & Unclear \\
\hline Mental rest & $\begin{array}{l}\text { SH } 2.14 .12 \\
\text { TM } 2.7 .13 \\
\text { SM } 2.3 .9\end{array}$ & All three practices & Unclear \\
\hline No discomfort & $\begin{array}{l}\text { SH } 2.14 .6 \\
\text { TM 2.7.31 } \\
\text { SM 2.3.23 }\end{array}$ & All three practices & Same \\
\hline No feeling of anxiety & $\begin{array}{l}\text { SH } 2.14 .22 \\
\text { TM } 2.7 .27 \\
\text { SM 2.3.21 }\end{array}$ & All three practices & Same \\
\hline
\end{tabular}

\subsection{Group 6 - bliss/goodness}

Wallace presents bliss as a feature of the Shamatha goal-state, and Pearson, Rosenthal and Roth treat it as part of the TM goal-state. Shear sometimes treats it as part of the TM goal-state (Shear 1990b, p.172, 2006b, p.xix, c, p.44, 2011a, pp.142-143), and other times he expressly states that it is not (Shear 1990a, p.396, 2002, p.378, 2014a, p.60). Shear claims that bliss is experienced in interim-states that immediately precede the TM goal-state (TM1.8.2). In one place he says that authors sometimes conflate these interim-states, where there is bliss, with the goal-state, where there is none (Shear 2002, p.378). He appears to be suggesting that this is the reason those authors incorrectly treat bliss as part of the goal-state. Travis, the final TM expert, tends not to refer to bliss.

In Shamatha and TM, bliss is also referred to as joy, happiness, and a sense of wellbeing. Wallace indicates that the bliss in Shamatha derives from the calm and peacefulness of the goal-state: It is experienced when the mind is no longer being "pummeled to death with afflictions, craving, hostility, and aversion" (Wallace 2010, p.32). 
He refers to it as the "joy of serenity" (Wallace 2005, p.109) and as a "bliss or joy that is quiet and serene" (Wallace 2011b, p.145). Rosenthal similarly identifies the close connection between the bliss, calm and peacefulness in the TM goal-state. He observes that peacefulness is one facet of bliss, alongside joy and happiness (Rosenthal 2016/2017, p.36), and he refers to bliss as "calm pleasure" (Rosenthal 2011/2012, p.38).

The bliss in the Shamatha goal-state is consistently presented as "subtle" (Wallace 1998/2005, p.207, 2005, p.109) and "subdued" (Wallace 2011b, p.145), and therefore vastly different to the intense bliss that is said to be experienced in the interim-state immediately prior to achieving the goal-state (SH1.11.10; Wallace 2006a, p.156, 2010, p.66, 2011a, p.97). For TM, on the other hand, there seems to be variation in how the magnitude or intensity of the bliss is described. For example, Pearson (2013, p.45) states that "[n]o experience fills the mind with greater happiness", and Shear (1990b, p.42) indicates that bliss is experiencing "the ultimate object of all desires". Rosenthal (2016/2017, p.39), in contrast, comments: "My own transcendent experiences and those of most of my patients are pleasant but unsensational". That suggests a more subdued experience of bliss than those referred to by Pearson and Shear.

The Stillness Meditation experts do not present "bliss" as a feature of the goal-states. However, they say that meditators experience the goal-states as good or wonderful, and as involving a sense of joy or wellbeing. In Shamatha and TM the term bliss is used synonymously with words like joy and wellbeing, and those terms can capture the sense that an experience is good or wonderful. As such, even though the word bliss is not relied on in Stillness Meditation, the feelings being described in that practice could be similar to those in Shamatha and TM.

As for Shamatha and TM, one source of the positive feelings in Stillness Meditation is said to be the calmness of the experience (Meares 1976/1980, p.134, 1978/1986, p.155). The Stillness Meditation experts also identify other sources, including the sense that the experience is effortless (Meares 1969c, p.84).

McKinnon (2002/2008, p.45) says that terms like "bliss ... rapture [and] exaltation" are not typically used to describe the Stillness Meditation goal-states, which suggests that the positive feelings in the goal-states are subdued in comparison to more intense forms. Meares states that "ecstasy" can be part of the Stillness Meditation experience, but he indicates that it is not a feature of the deepest goal-state (Meares 1976/1984, p.12, 1978/1986, p.145). It is unclear whether he means that ecstasy can be part of the shallower goal-states, or whether he is referring only to the interim-states. 
Table 6 Group 6 - Summary of Findings

\begin{tabular}{|c|c|c|c|}
\hline Feature of the goal-state/s & $\begin{array}{l}\text { Extraction table } \\
\text { section/s }\end{array}$ & Practices reported/implied in & $\begin{array}{l}\text { Are the goal-states the same or } \\
\text { different across the three practices } \\
\text { with respect to this feature? }\end{array}$ \\
\hline $\begin{array}{l}\text { Bliss, joy, happiness, } \\
\text { goodness, sense of } \\
\text { wellbeing }\end{array}$ & $\begin{array}{l}\text { SH } 2.14 .6 \\
\text { TM 2.7.26 } \\
\text { SM 2.3.19 }\end{array}$ & $\begin{array}{l}\text { All three practices, except } \\
\text { that Stillness Meditation does } \\
\text { not use the term bliss }\end{array}$ & Unclear \\
\hline
\end{tabular}

\subsection{Group 7 - luminosity}

Wallace refers to luminosity as a fundamental quality of consciousness. It is the quality that illuminates whatever appears to the mind and without which nothing would appear (Wallace 2011b, p.95, 2009/2014, p.90). According to Wallace (2018, p.44), the quality is normally obscured by the everyday content. In the Shamatha goal-state that content is no longer present. Luminosity is said to illuminate the resulting vacuity or emptiness (Wallace 2011b, pp.176-177, 2009/2014, p.90), and the luminosity is said to "[become] manifest" due to its being no longer obscured (Wallace 2018, p.44).

Wallace also treats luminosity as synonymous with vividness, which refers to the clarity of attention (Wallace 2011a, p.243, b, pp.120,186, 2012, p.17). It therefore appears that luminosity can describe both the vividness or clarity of attention with respect to appearances, and the quality that allows the meditator to be conscious of those appearances at all. Wallace seems to address the first aspect - vividness or clarity - when he comments that in the Shamatha goal-state there is an "exceptional degree of luminosity" (Wallace 2011a, p.232). We will discuss the vividness, or clarity, in Shamatha, TM and Stillness Meditation in section 3.16 .

Terms like clearness, purity, transparency, radiance, and limpidity are often relied on by Wallace in his comments about luminosity. These terms appear to refer to features of the Shamatha goal-state that are the same as those discussed elsewhere in this section 3 , or that are very similar. The words clear, pure and transparent are used, at least in places, to indicate the absence of everyday content (Wallace 2005, p.165, 2006a, p.144, 2011a, p.232, 2018, p.44). Clearness, therefore, does not necessarily equate to the term clarity, which tends to refer to vividness (e.g., Wallace and Hodel 2008, p.207). The terms radiance and radiant clarity are generally used as synonyms for luminosity, vividness and clarity (Wallace and Hodel 2008, p.192; Wallace 2011b, pp.98,120). Limpidity can indicate both the absence of everyday content and luminosity (Wallace 2001/2003, p.90).

The term luminosity is not used in the TM or Stillness Meditation accounts. Those accounts also do not clearly identify and label a particular quality of consciousness that 
illuminates appearances to the mind, as luminosity is said to do in Shamatha. It follows that there is no clear discussion in the accounts about whether that quality is noticed in the goalstates. Nevertheless, in the TM and Stillness Meditation goal-states the meditator is said to have a conscious experience of emptiness. Adopting the Shamatha understanding, that would mean that the emptiness in those goal-states is somehow illuminated, implying that there is a form of luminosity. It is possible that this quality is both present and noticed in the TM and Stillness Meditation goal-states, but that it is not labelled and commented upon in the texts for those practices as it is in Shamatha.

TM and Stillness Meditation use the words clear, clarity, and pure or purity (TM2.7.10-2.7.11; SM2.3.3), but those terms do not appear to add anything to the features of the goal-states discussed above and below. For example, the term pure consciousness is used heavily in TM. The word pure in that context refers to the absence of everyday content in the TM goal-state, and to the understanding that the experience is of consciousness itself. As a further example, the term clarity in Stillness Meditation suggests that the goal-states involve a degree of vividness and are not drowsy. We discuss vividness in section 3.16 , and the absence of drowsiness is incorporated in the understanding that the meditator has a heightened level of wakefulness.

Table 7 Group 7 - Summary of Findings

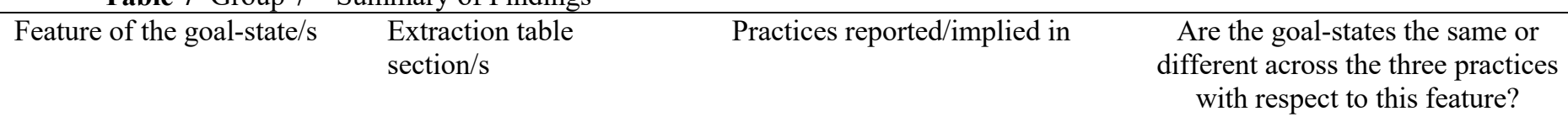

Luminosity as a quality that $\quad$ SH 2.14 .7

illuminates the emptiness

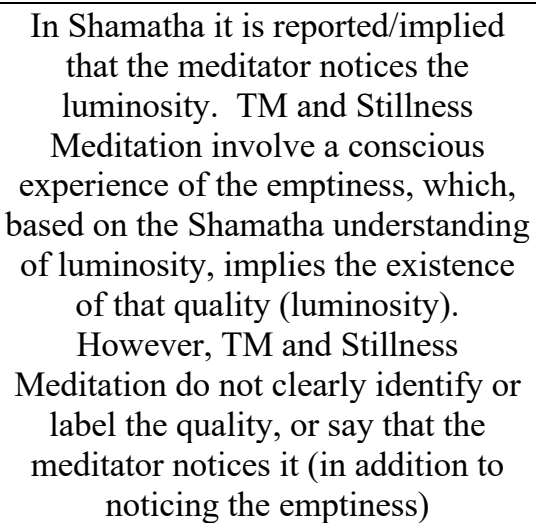
noticing the emptiness)

Note. The table does not include "Luminosity as vividness" as a feature, since it is understood to be equivalent to "Attentional vividness" as referred to in Table 16.

\subsection{Group 8 - knowledge/knowing}

Wallace treats cognizance or knowing as another fundamental quality of consciousness alongside luminosity. Luminosity illuminates appearances such as thoughts and images, whereas cognizance is the quality of knowing that they are there and recognizing 
them for what they are (Wallace 2005, p.37, 2011a, p.229). The Shamatha goal-state is said to be empty, but the quality of knowing remains. Wallace describes it as a knowing that the mind is empty (Wallace 2009/2014, p.90), "knowledge before knowledge of anything else" (Wallace 2005, p.191), and "the very nature of [knowing]" (Wallace 1999b, p.444). He also refers to it as a "nonconceptual knowing" (Wallace 2011a, p.297) and a "deep knowledge that is implicit rather than explicit" (Wallace 2011a, p.187).

TM and Stillness Meditation also refer to some sort of knowing or knowledge in the goal-states. Pearson (2013, p.47) notes that Maharishi Mahesh Yogi, who first brought TM to the west, referred to the TM goal-state as involving "pure knowledge" or a "state of knowingness". Pearson contrasts that with the "knowledge of specific things" that is a feature of consciousness in normal life (p.47). Rosenthal (2011/2012, p.39) quotes a meditator who says that in the TM goal-state they experience "a knowing that is very beautiful". The Stillness Meditation accounts also refer to a form of knowing or knowledge that is different to the types experienced in normal life. Meares (1987a, p.9) describes it as "the spirit of what we need to know [r]ather than knowledge itself". Like in Shamatha, he emphasizes that this knowledge is beyond thoughts and words (Meares 1979b, p.81, 1980e, p.3, 1976/1984, pp.22-23).

Table 8 Group 8 - Summary of Findings Feature of the goal-state/s Extraction table section/s

Practices reported/implied in Are the goal-states the same or different across the three practices with respect to this feature?

Knowledge/knowing $\quad$ SH 2.14 .8

\subsection{Group 9 - relinquishment of control, control, effortlessness}

Relinquishment of control is presented as a fundamental element of each practice. A basic principle is that the meditator relinquishes control in the interim-states in order to move into the goal-state/s. The Shamatha and TM accounts contain little reference to the meditator having a sense of the relinquishment of control in the goal-state/s. However, it is clear from those accounts that the meditator does not reassert control in the goal-states, which suggests that they would describe those states as involving the relinquishment of control. The Stillness Meditation accounts establish more clearly that the meditator has a sense of the relinquishment of control in the goal-states.

The main type of control that the three practices refer to as having been relinquished is deliberate control. The experts tend not to use that specific term, but it provides a useful 
shorthand for what they are describing. Control can be thought of as the guiding of mental or physical experience or action (Christoff et al. 2016; Markovic and Thompson 2016). In the goal-states, there is no deliberate doing, or guiding. For example, upon reaching the Shamatha goal-state, the meditator has eliminated excitation and laxity, and therefore no longer needs to monitor to detect them. ${ }^{9}$ In the TM goal-state the meditator has transcended the mantra, so does not need to return their attention to it. The Stillness Meditation practitioner has from the beginning relinquished all deliberate doing and control, other than that required to maintain the posture. Once their body comes to automatically remain in the correct posture, deliberate doing and control are not required for that either.

Meares provides detailed descriptions of the relinquishment of an additional form of control in Stillness Meditation (Meares 1967/1968, pp.87-88, 1978/1986, pp.27-29,147). It is clear from these descriptions that what is being relinquished is a form of automatic control, although Meares does not use that particular term. He notes, for example, that the control does not come from the "voluntary level of [the] mind" (Meares 1978/1986, p.29).

Experientially, the meditator finds that with each session they can progress a little further, either towards the goal-states, or into deeper goal-states. For example, Meares (1978/1986, p.147) describes the "letting go of ourself" that is initially experienced in the goal-states, and the "deeper process of simply 'letting ourself" that is subsequently encountered. McKinnon (1983/2016, p.227) refers to the relinquishment of automatic control in the goal-states by saying, "You let go into [the stillness] more and more and more completely". The meditator has the sense that previously there was something holding them back: a form of automatic control exerted over themselves. With practice, they are able to relinquish that control in whole or in part, allowing them to progress.

Certain of Wallace's descriptions in Shamatha could arguably also be interpreted as indicating a relinquishment of this form of automatic control (e.g., Wallace 2006a, p.100, read together with Wallace, 2011a, pp.179-184). However, neither Wallace's account nor the TM passages refer to this relinquishment clearly and directly, as done in Stillness Meditation. Given that relinquishment of control is regarded as fundamental in Shamatha and TM, it seems plausible that the relinquishment of automatic control described in Stillness Meditation is also part of those practices. 
In Stillness Meditation, relinquishing the automatic control in the goal-states allows the meditator to go deeper, until they reach the deepest goal-state. In Shamatha and TM, whether the meditator can go deeper in the goal-state/s in a similar way depends on whether the goal-state/s are understood as a single state or a series of deepening states. If there is no deepening in the goal-states, it could still be that the relinquishment of automatic control and the associated deepening of experience occur in the interim-states.

The Stillness Meditation experts indicate that the meditator may also have some sense of calm control in the goal-states. The meditator maintains the posture throughout the practice, which requires a form of automatic control different to that referred to in the paragraphs above. Meares (1978/1986, p.40) explains that maintaining the posture leads to the "simultaneous experience of complete relaxation and effortless control", and McKinnon $(2011$, pp.67,81) refers to this as "calm control".

The Shamatha and TM accounts do not refer to this sense of calm control in the goalstates. However, both those practices appear to require forms of automatic control during those states: In each practice the posture is maintained, and in Shamatha there is singlepointed attention. It therefore seems plausible that meditators in those practices also have some sense of calm control, even though the experts do not mention it.

In Shamatha, the goal-states are referred to as effortless and as involving no effort, and in TM and Stillness Meditation the entire practices are described that way (see further Woods et al. 2021). In each practice, it is clear from the expert texts that, since there is no deliberate doing/control in the goal-states, there is no effort associated with such doing/control, and the goal-states are therefore effortless in that sense. The Stillness Meditation texts arguably indicate that there are subtle forms of effort associated with the form of automatic control that is relinquished in the goal-states. On that understanding, in the deepest goal-state (where much or all of that automatic control has been relinquished) there is an even greater effortlessness than in the shallower goal-states. McKinnon (2002/2008, p.45) says that the deepest goal-state is "beyond effort ... of any kind". It is plausible that all three practices involve the release of subtle forms of effort linked to the relevant form of automatic control, but the textual evidence on this point is inconclusive.

Table 9 Group 9 - Summary of Findings

\begin{tabular}{|c|c|c|c|}
\hline Feature of the goal-state/s & $\begin{array}{l}\text { Extraction table } \\
\text { section/s }\end{array}$ & Practices reported/implied in & $\begin{array}{l}\text { Are the goal-states th } \\
\text { different across the thr } \\
\text { with respect to this }\end{array}$ \\
\hline No deliberate doing & $\begin{array}{l}\text { SH } 1.10,2.14 .29 \\
\text { TM 1.6, 2.7.29 } \\
\text { SM 1.8, 1.12, 2.3.28 }\end{array}$ & All three practices & Same \\
\hline
\end{tabular}


No deliberate control

Relinquishment of a form of automatic control the meditator exerts over themselves

Calm control

Effortlessness
SH 1.10, 2.14.29

TM 1.6, 2.7.29

SM 1.8, 1.12, 2.3.26

SM 1.15.3, 2.3.26

SM 1.12, 2.3.26

SH $1.10,2.14 .29$

TM 1.6, 2.7.29

SM 1.8, 1.12, 2.3.25
All three practices

Same

Stillness Meditation

Unclear

Stillness Meditation

Unclear

All three practices

Unclear

\subsection{Group 10 - ego dissolution, freedom, spaciousness}

Loss of ego is referred to as a feature of the goal-states in all three practices. Wallace states that in the Shamatha goal-state there is no ego, sense of self, sense of "I" or "mine", or personal history or identity. The TM passages are similar, referring to the TM goal-state/s as beyond ego, sense of self, sense of "I" or "me", personality, and individuality. McKinnon says that in the Stillness Meditation goal-states there is no ego.

Meares and McKinnon indicate that meditators can experience a loss of self/world boundaries in the Stillness Meditation goal-states. Meares (1978/1986, pp.152-153) explains that meditators may report a sense of merging with the world around them, and McKinnon (2011, p.118) describes the sense of "communion with all things". In TM there are also explicit descriptions of the loss of self/world boundaries (Shear 1990b, p.230; Rosenthal $2011 / 2012$, p.37), and the word unbounded is frequently used without elaboration.

Wallace does not expressly refer to a loss of self/world boundaries in the Shamatha goal-state. He does, however, describe the goal-state as involving freedom, spaciousness, and unity, and it is possible that the loss of boundaries is incorporated in one or more of those features. Wallace does not describe the three features in much detail.

The experience of inner freedom is also reported in TM and Stillness Meditation. The term freedom is usually used in Stillness Meditation to describe the meditator's sense that there is nothing holding them back within the experience. That appears to reflect that the meditator has relinquished all deliberate control and, at a certain point, will have relinquished the relevant form of automatic control. In TM the term freedom similarly relates to the absence of limitations or restraints (Travis et al. 2005, p.128; Pearson 2013, p.396). These include self/world boundaries (Shear 1990b, p.230), and presumably also relevant forms of control. 
Describing the Stillness Meditation goal-states, McKinnon (2011) refers to "spaciousness and comforting enclosure" (p.81), and an experience that is "closed yet spacious" (p.101). She does not elaborate on what she means by the terms spacious, enclosure or closed. The TM experts do not use the term spacious to describe the TM goalstate, and the terms enclosure and closed are not used in TM or Shamatha.

Wallace describes the ego as the sense of "I am", and repeatedly indicates that this will be strengthened by any deliberate doing or control on the part of the meditator (Wallace 2006a, p.49, 2011a, pp.179-184). As discussed above, the experts in all three practices make clear that there is no deliberate doing or control in the goal-states, which implies the complete loss of any sense of self derived from such doing or control.

The Stillness Meditation texts may be read as indicating that there is a sense of self that derives from the form of automatic control that is said to be relinquished in the goalstates in that practice. That sense of self could be understood as including the self/world boundaries referred to above, but there may also be other facets (see Meares 1978/1986, pp.145-160). As noted above, it is possible that Shamatha and TM also involve a relinquishment of the relevant form of automatic control. To the extent that there is a sense of self that derives from that control, the relinquishment of the control in a practice will lead to loss of that sense of self.

While the TM and Stillness Meditation experts refer to there being no ego in the goalstates, and the TM experts at times indicate that there is no sense of self, in both practices meditators may describe the goal-states (or at least the deepest goal-state) as an experience of their true self (see section 3.14 below). This suggests that certain dimensions of self are lost in the goal-states but that a deeper sense of self may be revealed. The Shamatha texts do not refer to the goal-state in that practice as involving an experience of the true self.

Table 10 Group 10 - Summary of Findings

\begin{tabular}{llcc}
\hline Feature of the goal-state/s & $\begin{array}{l}\text { Extraction table } \\
\text { section/s }\end{array}$ & Practices reported/implied in & $\begin{array}{c}\text { Are the goal-states the same or } \\
\text { different across the three practices } \\
\text { with respect to this feature? }\end{array}$ \\
\hline Loss of ego & SH $1.10,2.14 .32$ & All three practices & Unclear \\
& TM 2.7 .33 & & Unclear \\
SM 2.3 .27 & TM and Stillness Meditation & \\
Loss of self/world & TM 2.7 .39 & All three practices & Unclear \\
boundaries & SM 2.3 .32 & &
\end{tabular}


Note. The true self feature is addressed in Table 14.

\subsection{Group 11 - integration and security}

In each practice the experts indicate that the goal-states involve a sense of wholeness, unity, and integration or coherence. TM and Stillness Meditation emphasize this aspect more than Shamatha, but in Shamatha there are still clear references to it.

The four qualities are often referred to briefly, without elaboration. The elaboration that is provided suggests that the qualities may have multiple facets. For example, Rosenthal (2016/2017, p.234) and Meares (1978/1986, pp.19-20) refer to the sense of unity from transcending the duality between subject and object; Meares (1978/1986, p.149) talks about the unity of no longer experiencing body and mind as separate; and Wallace (2011a, p.208) notes the unity between awareness and the emptiness, brought about by the absence of everyday content. McKinnon (2011, pp.85,118,203, 1983/2016, p.195) refers to the meditator's sense of integration, coherence and unity both within themselves, and with the world around them. The latter aspect reflects the loss of self/world boundaries described in section 3.10 .

Certain of the features discussed in the sections above, such as calm, peacefulness, bliss, joy, and no feeling of anxiety, suggest some sense of inner security, safety, strength and contentment. Those latter four qualities are also clearly and repeatedly referred to in TM and Stillness Meditation. For example, in the TM context one meditator refers to feelings of strength, invincibility, and being taken care of (Pearson 2013, p.185), and another comments that "Everything seems right" (Travis et al. 2005, p.128). McKinnon (2011) similarly refers to the Stillness Meditation experience as involving "a very safe and content knowledge that all is well" (p.101), and she quotes a meditator saying that, "Everything I needed - safety, security, strength, peace - was within that stillness" (p.102).

In Shamatha, Wallace tends not to emphasize security, safety, strength and contentment beyond what is suggested by the features calm, peacefulness, bliss, and so on. He does, however, quote nineteenth-century Buddhist contemplative Lerab Lingpa as saying that the experience can provide "a non-conceptual sense that nothing can harm the mind" (Wallace 2012/2014, p.218). 
Table 11 Group 11 - Summary of Findings

\begin{tabular}{lllc}
\hline Feature of the goal-state/s & $\begin{array}{l}\text { Extraction table } \\
\text { section/s }\end{array}$ & Practices reported/implied in & $\begin{array}{c}\text { Are the goal-states the same or } \\
\text { different across the three practices } \\
\text { with respect to this feature? }\end{array}$ \\
\hline Integration/coherence & $\begin{array}{l}\text { SH } 2.14 .34 \\
\text { TM } 2.7 .37\end{array}$ & All three practices & Unclear \\
SM 2.3 .30 & All three practices & Unclear \\
Wholeness & As for row above & All three practices & Unclear \\
Unity & As for row above & All three practices & Unclear \\
Security/safety & SH $2.14 .6,2.14 .22$, & & Unclear \\
Strength & TM 2.7 .38 & All three practices & All three practices \\
SM 2.3 .31 & As for row above & As for row above &
\end{tabular}

\subsection{Group 12 - timelessness and spacelessness}

In each practice the goal-states are said to be timeless. Wallace (2006a, p.162) says that the Shamatha meditator may have "little or no experience of the passage of time". Wallace explains that sense of time is dependent on conceptualization, and refers to the absence of conceptualization in the Shamatha goal-state. He notes, however, that before entering the goal-state the meditator can cue themselves to emerge after a specified period or when prompted by an external stimulus such as an alarm clock.

The Shamatha practices conclude with the Shamatha goal-state, but if the meditator wishes they may proceed to deeper states via separate practices (see, e.g., Lati Rinbochay and Denma Lochö Rinbochay 1983/1997; Wallace 1998/2005, p.92, 2010, pp.84-85*). ${ }^{10}$ Wallace (2011a, p.292) indicates that there are gradations of timelessness, and that timelessness becomes more complete as a meditator moves from the goal-state through the series of deeper states. He refers to time having vanished in each of these states, but indicates that it is only at the end of the series that "time is completely stopped" (p.292).

The TM goal-state is referred to as being "beyond time" (Rosenthal 2011/2012, p.18; Pearson 2013, p.265) and "devoid of [temporal] content" (Shear 1990a, p.392). However, Roth (2018, p.58) notes that many TM meditators say that "time passes quickly". That comment suggests that the meditators emerge from the goal-state and discover that more clock-time has passed than the way it feels when reflecting on the experience. This raises the

$10 \quad$ These states are the deeper absorptions as referred to in section 4.7. 
possibility that, although the goal-state is in some sense timeless, there is still some temporal content.

Meares and McKinnon say relatively little about time and the Stillness Meditation goal-states. Meares (1976/1980, p.190) simply observes that sense of time is distorted, and McKinnon's main comment is that the states are timeless.

In summary, it appears that the goal-states in all three practices are in some sense timeless, but it is not clear exactly what is meant by that term, and in particular whether all temporal content is absent. ${ }^{11}$

TM experts say that the goal-state involves no sense of space. Shear (1990a, p.392), for example, says that "by all accounts ... spatiality ... [is] not present", and Rosenthal (2011/2012, p.18) refers to the feeling of going beyond space. As discussed above, Wallace and McKinnon describe the goal-states in Shamatha and Stillness Meditation as spacious, but it is not clear exactly what they mean by that term. Wallace and the Stillness Meditation experts do not clearly refer to all sense of space being absent.

Table 12 Group 12 - Summary of Findings

\begin{tabular}{llcc} 
Feature of the goal-state/s & $\begin{array}{l}\text { Extraction table } \\
\text { section/s }\end{array}$ & Practices reported/implied in & $\begin{array}{c}\text { Are the goal-states the same or } \\
\text { different across the three practices } \\
\text { with respect to this feature? }\end{array}$ \\
\hline $\begin{array}{l}\text { Timeless (although not } \\
\text { necessarily entirely devoid } \\
\text { of temporal content) }\end{array}$ & $\begin{array}{l}\text { SH 2.14.37 } 2.7 .41 \\
\text { SM } 2.3 .33\end{array}$ & All three practices & Unclear \\
No sense of space & TM 2.7 .40 & TM & Unclear \\
\hline
\end{tabular}

\subsection{Group 13 - spiritual aspect and energy}

In each practice the experts indicate that some meditators may report there having been some spiritual aspect of the goal-states. For example, Wallace discusses the possibility of meditators referring to the Shamatha goal-state as "[belonging] to God" (Wallace 2009/2014, p.59), or "holy" (Wallace 2011b, p.159). Rosenthal (2011/2012, p.38) quotes a meditator referring to the TM goal-state as "a touch of heaven", and Pearson (2013, p.264) notes that Maharishi Mahesh Yogi regarded it as an aspect of God. Meares (1984, p.147) says that meditators have reported that in the Stillness Meditation goal-states they have gained glimpses of a "[spiritual] dimension of [their] being".

The Shamatha and Stillness Meditation accounts indicate that two meditators may have the same experience but interpret it differently (Meares 1984, p.47; Wallace 2009/2014,

11 One possibility is that in the goal-states in some or all of the practices meditators have an extended experience of "nowness", as described by Windt (2015). 
p.59). One may interpret some facet of the experience as spiritual, while another may interpret it simply as one of the features discussed above and below. It is not clear from the accounts in the three practices whether it is possible for the spiritual element to be something beyond those features.

Rosenthal (2016/2017, pp.217,221-222) quotes two meditators who refer to a sense of energy flowing through them in their TM practice. However, those people also refer to having sense or body perceptions, which suggests that they may be describing interim rather than goal states. Roth, in the TM context, and Wallace, in Shamatha, also refer to energy as an aspect of the states aimed for in those practices. It is not clear, though, from those references whether energy is a feature of the goal-states that is distinct from those discussed above and below. For example, Wallace says that the Shamatha state "possesses structure and energy, characterized by such attributes as bliss ... luminosity ... and [subject-object nonduality]" (Wallace and Hodel 2008, p.192). That statement does not establish that the meditator has a sense of energy over and above those other features, but it does not rule it out either.

In Stillness Meditation energy is not referred to as being part of the states aimed for in the practice. McKinnon (2011, p.108*) says that in those states "all energy is resting".

Table 13 Group 13 - Summary of Findings

\begin{tabular}{llcc}
\hline Feature of the goal-state/s & $\begin{array}{l}\text { Extraction table } \\
\text { section/s }\end{array}$ & Practices reported/implied in & $\begin{array}{c}\text { Are the goal-states the same or } \\
\text { different across the three practices } \\
\text { with respect to this feature? }\end{array}$ \\
\hline Spiritual aspect & SH 2.14.39 & All three practices & Unclear \\
& TM 2.7.43 2.3 .35 & Shamatha and TM & Unclear \\
Energy & SH 2.14.40 & & \\
& TM 2.7.44 &
\end{tabular}

\subsection{Group 14 - ground-state}

Wallace describes the Shamatha goal-state as a "ground state" of consciousness or the mind. He refers to it as the "relative" ground-state, and distinguishes that from pristine awareness, the "absolute" or "ultimate" ground-state accessible via more advanced practices (SH2.6; Wallace 2006a, p.137, 2011b, p.27). Wallace calls the Shamatha goal-state the natural state, or the essential nature, of the mind (SH2.14.30; Wallace 2012/2014, p.151), and notes that a meditator may interpret it as a deep dimension of their being (Wallace 2009/2014, p.59). He explains that, in the Shamatha context, the term essential nature of the mind refers to the mind's relative or conventional nature (Wallace 2011b, p.177). The term 
can also be used to describe pristine awareness, but there it means the mind's ultimate or fundamental nature (Wallace 2006a, p.137).

Pearson, Shear and Travis indicate that, like in Shamatha, the TM goal-state is a ground-state of consciousness or the mind. In Stillness Meditation the experts do not use the term ground-state. However, Meares refers to the "full" (Meares 1978/1986, p.145) or "final" (Meares 1987/1991, p.127) experience in the practice, and McKinnon (2002/2008, p.45) speaks about the "ultimate sensation". Viewed in context, these passages appear to be referring to the deepest goal-state among a range of Stillness Meditation goal-states (see further section 3.18). This deepest goal-state could be treated as a ground-state.

Similarly to Shamatha, in the TM and Stillness Meditation ground-states the meditator is said to experience the essential nature of their mind or being. In all three practices, the features of the goal-states such as stillness, calm, and naturalness are presented as aspects of that essential nature. In other words, those features are depicted as innate: Meditators have the sense of discovering them within themselves, and of recognizing that they have been there all along.

In places, the TM and Stillness Meditation experts indicate that the respective groundstates are the simplest and most natural experience/s possible (Meares 1984, p.52, 1978/1986, p.27; Pearson 2013, pp.44,49). Wallace states that in the Shamatha ground-state the meditator experiences "utter simplicity" (Wallace 2005, p.189), and his labelling of it as the natural state of the mind suggests a very high degree of naturalness. Unlike in Shamatha, the TM and Stillness Meditation experts do not refer to there being any deeper ground-state accessible via other meditation practices.

Wallace describes the Shamatha goal-state as consciousness or awareness itself, and Pearson, Shear and Travis say the same of the TM goal-state. Pearson, Shear and Travis use the term pure consciousness in this context, whereas Wallace does not. Wallace (2006a, p.123) emphasizes that the Shamatha goal-state is "the nature of consciousness in its relative ground state". From the Shamatha perspective, pristine awareness is the ultimate nature of consciousness (SH2.6). In contrast to Shamatha and TM, the Stillness Meditation groundstate is not described as consciousness or awareness itself.

In TM and Stillness Meditation the ground-states are referred to as simple or pure being. Rosenthal (2016/2017, pp.238-239) quotes a TM meditator saying, "It's pure being. It's is-ness, pure am-ness. It is the essential nature of existence”. Meares (1978/1986, p.27) explains similarly that the Stillness Meditation ground-state is "the unadorned, primordial experience of existence": "the act of just being ... with nothing added at all". In TM and 
Stillness Meditation, the ground-states are also described as an experience of the true, underlying, innermost, or deepest self. When discussing simple/pure being or the self, the TM experts sometimes use title case, referring to Being and Self (capitalized). In places they do this to make clear that the experiences of being and self are different to those in everyday life (Arenander and Travis 2004, p.114; Shear 2006b, p.xvii; Pearson 2013, p.46). They may also do it, at least in places, to hint at metaphysical aspects of the experience (Shear and Jevning 1999a, p.193; Shear 2006b, p.xix; TM2.4). Wallace does not describe the Shamatha ground-state as simple or pure being, or as the self.

In a small number of passages Meares indicates that in the Stillness Meditation ground-state the meditator is beyond calm, stillness and/or the sense that the experience is good. ${ }^{12}$ The passage that makes this point most clearly relates to the experience of calm. Meares (1976/1984, p.36) says: "When being comes we are beyond calm. How could you be calm [i]f you were simply being?". The passages could be read as indicating that the ground-state is different from other Stillness Meditation goal-states, in that in the groundstate there is no experience of calm, stillness or goodness. However, Meares' broader comments concerning the ground-state give the impression that, having experienced it, the meditator would still recognize that their mind had been calm and still and regard the experience as positive. Furthermore, McKinnon (2002/2008, p.45) refers to the ground-state as involving a "calm sense of [being]". These broader passages raise the possibility that the ground-state in some sense involves calm, stillness and goodness, but in another sense is beyond them. As the discussion in this paragraph illustrates, it is not clear from the Stillness Meditation accounts exactly how the ground-state is beyond these features.

In the Shamatha accounts there is nothing to suggest that the ground-state is somehow beyond calm, stillness or bliss. There is also little in the TM accounts, other than Shear's minority understanding that the TM goal-state involves no or virtually no content other than being conscious and awake. It seems possible that, similar to what Meares describes, there are a series of TM goal-states, and that the deepest state is somehow beyond content such as calm, stillness and bliss. That might provide a way to reconcile Shear's minority understanding with the more widely held view of the TM experts that those types of content are present in the TM goal-state. This possibility is, however, not something that is explicitly canvassed in the TM accounts.

12 It is possible that Meares refers to calm, stillness and goodness in this context merely because they are more prominent features of the meditation experience, and that he actually considered that the groundstate is also beyond certain other features discussed above and below. 
Table 14 Group 14 - Summary of Findings

\begin{tabular}{|c|c|c|c|}
\hline Feature of the goal-state/s & $\begin{array}{l}\text { Extraction table } \\
\text { section/s }\end{array}$ & Practices reported/implied in & $\begin{array}{l}\text { Are the goal-states the same or } \\
\text { different across the three practices } \\
\text { with respect to this feature? }\end{array}$ \\
\hline
\end{tabular}

\begin{tabular}{|c|c|c|c|}
\hline $\begin{array}{l}\text { A ground-state of } \\
\text { consciousness or the mind }\end{array}$ & $\begin{array}{l}\text { SH 2.14.31 } \\
\text { TM 2.7.36 }\end{array}$ & $\begin{array}{l}\text { Shamatha and TM experts } \\
\text { describe the goal-state as a ground- } \\
\text { state. The Stillness Meditation } \\
\text { experts imply that there is a } \\
\text { deepest goal-state. This could be } \\
\text { treated as a ground-state }\end{array}$ & Unclear \\
\hline $\begin{array}{l}\text { The ground-state is the } \\
\text { essential nature of the } \\
\text { mind or being }\end{array}$ & $\begin{array}{l}\text { SH 2.1.4, 2.14.30 } \\
\text { TM 2.7.36 } \\
\text { SM 2.3.29 }\end{array}$ & All three practices & Unclear \\
\hline $\begin{array}{l}\text { The ground-state is } \\
\text { extremely simple and natural }\end{array}$ & $\begin{array}{l}\text { SH } 2.14 .30,2.14 .33 \\
\text { TM 2.7.32, 2.7.34 } \\
\text { SM 2.3.28-2.3.29 }\end{array}$ & All three practices & Unclear \\
\hline $\begin{array}{l}\text { The ground-state is } \\
\text { consciousness itself }\end{array}$ & $\begin{array}{l}\text { SH } 2.14 .3 \\
\text { TM } 2.7 .4\end{array}$ & Shamatha and TM & Unclear \\
\hline $\begin{array}{l}\text { The ground-state is } \\
\text { simple or pure being }\end{array}$ & $\begin{array}{l}\text { TM 2.7.35 } \\
\text { SM 2.3.28 }\end{array}$ & TM and Stillness Meditation & Unclear \\
\hline $\begin{array}{l}\text { The ground-state is the } \\
\text { true or deepest self }\end{array}$ & $\begin{array}{l}\text { TM 2.7.36 } \\
\text { SM 2.3.29 }\end{array}$ & TM and Stillness Meditation & Unclear \\
\hline $\begin{array}{l}\text { The ground-state is in some } \\
\text { sense beyond calm, stillness } \\
\text { and goodness }\end{array}$ & 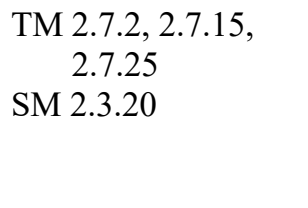 & $\begin{array}{l}\text { Stillness Meditation. Potentially } \\
\text { compatible with Shear's minority } \\
\text { understanding that the TM goal-state } \\
\text { has no or virtually no content other } \\
\text { than being conscious and awake }\end{array}$ & Unclear \\
\hline
\end{tabular}

Note. For simplicity and ease of communication, in this section we have treated the ground experience in each practice as a single state. In reality, it appears there can be variation in that experience (see section 3.18).

\subsection{Group 15 - deep and profound}

Wallace describes the Shamatha goal-state as deep, while noting that pristine awareness is understood to be the deepest level of the mind or consciousness (SH2.14.41, 2.6). Roth, Shear and Travis treat the TM goal-state as the deepest level of consciousness, being or self. Meares (1976/1984, p.52, 1978/1986, p.49) describes even the most basic Stillness Meditation goal-states as deep, in that they involve almost no everyday content. He and McKinnon present the goal-states as deepening as the meditator moves towards the ground-state.

The experts in the three practices refer to particular features of the goal-states, such as stillness, silence or calm, as being deep. At other times they state simply that the goal-states are deep, which suggests depth with respect to multiple features. 
The basic understanding conveyed by the experts in the three practices is that the meditator experiences the goal-states as profound. Wallace notes that the Shamatha goalstate is a "faint facsimile" of enlightenment (pristine awareness) (Wallace 2011b, p.121). However, he says that the goal-state is itself "remarkable" (Wallace 2011b, p.159) and a "major transformation of consciousness" (Wallace 1989/2003, p.150), and can therefore be very easily mistaken for enlightenment. The TM goal-state is frequently described as profound, remarkable, or extraordinary. Meares (1978/1986, p.26) depicts even the basic Stillness Meditation goal-states as an "experience of the highest order" that "far transcends the ordinary experience of life". Meares and McKinnon also refer to numerous features of the goal-states, such as the stillness, calm and simplicity, as profound. In TM and Stillness Meditation it is emphasized that the profundity of the experiences is not due to their being flashy, or strange and dramatic. The goal-states are instead described as simple and natural, as discussed above.

Although the basic understanding is that the TM and Stillness Meditation goal-states are profound, there are some indications that this may not always be the case. For example, Roth (2018, p.45) says that "Sometimes the experience in TM is profound; oftentimes it can seem mundane". Rosenthal (2016/2017, p.39), as noted above, describes his and others' experiences of the TM goal-state/s as "pleasant but unsensational". In McKinnon (2011, p.164) it is noted that, having emerged from the Stillness Meditation goal-states, some meditators may query whether such a simple experience can lead to the benefits referred to in that tradition. If meditators were always experiencing the goal-states as profound, it seems curious that they would have that query.

One way of understanding the TM and Stillness Meditation descriptions in the paragraph above is that they refer to shallower goal-states that are not experienced as profound. Another possibility is that all of the goal-states are profound, and that, although the non-profound experiences are sometimes presented as goal-states, they are in fact interimstates. It is not clear from the extracted text which of these understandings is correct, or whether they both apply to some degree.

Table 15 Group 15 - Summary of Findings

\begin{tabular}{|c|c|c|c|}
\hline Feature of the goal-state/s & $\begin{array}{l}\text { Extraction table } \\
\text { section/s }\end{array}$ & Practices reported/implied in & $\begin{array}{l}\text { Are the goal-states the same or } \\
\text { different across the three practices } \\
\text { with respect to this feature? }\end{array}$ \\
\hline
\end{tabular}


Note. ${ }^{a}$ More precisely, the Shamatha and TM goal-states are deeper on the dimension of depth that concerns loss of perceptions. It is possible that they are equally or less deep on other dimensions of depth.

\subsection{Group 16 - attention}

Wallace indicates that in the Shamatha goal-state attention is on what he variously describes as the emptiness, vacuity, absence of appearances, quiescence, mind, and consciousness. The TM experts state similarly that in the TM goal-state attention is on what they refer to as consciousness or mental silence. It is clear from the Shamatha and TM passages that the experts are using the different terms such as emptiness, consciousness and silence to refer to what is being experienced as a whole. When they say, for example, that attention is on the silence, they mean that attention is on what is being experienced overall, including emptiness, silence, and so on, not that attention is on the silence as a specific facet of the overall experience. For clarity, in the discussions concerning attention in the remainder of this paper, we will refer to what is being experienced overall as the emptiness/silence. ${ }^{13}$

When addressing the Stillness Meditation goal-states within the discussions, we will, for simplicity, deal only with the deeper goal-states, where even very dull perceptions are absent. The Stillness Meditation experts do not expressly state that attention is on the emptiness/silence. However, as in Shamatha and TM, in the Stillness Meditation goal-states the meditator is said to experience the emptiness/silence alone, without everyday content. That implies that the meditator's attention is on the emptiness/silence, like in Shamatha and TM.

The next point to consider is the nature or quality of the attention on the emptiness/silence in the three practices. In the Shamatha goal-state the meditator is said to have "exceptional" (Wallace 2006a, p.159) or "perfect" (Wallace and Hodel 2008, p.212) stability and vividness of attention. The exceptional stability is such that attention can remain on the emptiness/silence for four or more hours without the slightest deviation (Wallace 1989/2003, p.196, 2011b, p.ix). Another way of describing this stability is by saying that attention is focused on the emptiness/silence "single-pointedly like a laser" (Wallace 2001/2003, p.133). Wallace states that traces of everyday content may occasionally arise, but

13 The term emptiness/silence is necessary because the term goal-state is too broad in this context. It would be incoherent to say that the meditator's attention is on the goal-state, since attention is part of the goal-state. It is fine to say that the meditator's attention is on the emptiness/silence. 
he indicates that this only occurs where the meditator fails to maintain single-pointed attention (Wallace 2006a, p.161; Wallace and Hodel 2008, p.212). Since he presents singlepointed attention as a key feature of the Shamatha goal-state, in this analysis we will assume that it is maintained. Exceptional vividness means that the emptiness/silence is experienced with perfect clarity or focus, without even the slightest dullness (SH1.5.4, 1.7.3, 2.14.27; Wallace 1989/2003, p.196).

In Shamatha, the meditator cultivates the exceptional stability and vividness methodically over the course of the interim-states. They develop the stability principally by eliminating excitation, and the vividness by overcoming laxity/dullness. The main way to counteract excitation is to relax, and the main antidote to dullness is to arouse attention. The exceptional stability and vividness of the goal-states can be maintained without effort (Wallace 2011b) because they have been cultivated methodically.

For a meditator who has reached the TM or Stillness Meditation goal-state/s, a meditation session is said to involve repeatedly moving into and out of that experience. In TM this is referred to as "cycling" in and out (Travis 2011, p.229; Faber et al. 2017, p.313), and in Stillness Meditation it is characterized as an "ebb and flow" (Meares 1989, p.17; McKinnon 1983/2016, p.221). Within a meditation session, the movement out of the goalstate/s is said to be beyond the meditator's control, but with continued practice it tends to occur less frequently, meaning that the periods in the goal-state/s lengthen.

Where the TM or Stillness Meditation practitioner is able to stay in the goal-state/s for extended periods, this implies a degree of stability in the experience of the emptiness/silence. However, the fact that experienced meditators will still move out of the goal-state/s multiple times in a session indicates that there is substantially less stability than in Shamatha. Movement out of the goal-state/s occurs where the meditator experiences everyday content. That appears to entail the meditator's attention moving from the emptiness/silence to that content to some degree.

The lesser stability in TM and Stillness Meditation fits with the understanding that the Shamatha meditator develops single-pointed attention by cultivating it methodically in the interim-states. It is clear from the TM and Stillness Meditation accounts that the cultivation of single-pointed attention is not part of those practices (see Woods et al. 2021). In Stillness Meditation the meditator makes no effort to focus attention. In TM, the meditator brings attention to the mantra to prompt the mind to move automatically towards the goal-state/s. 
After that initial prompting, any deliberate focusing of attention is abandoned. ${ }^{14}$ The goalstates in the two practices are in places referred to as involving an absence of focus.

The TM and Stillness Meditation experts tend not to use the terms vivid or vividness in describing the goal-states. However, in both practices the goal-states are said to involve clarity, and to be clear or "crystal clear" (Meares 1983a, p.118; Pearson 2013, p.26). In most places there is ambiguity as to whether the experts use these terms to refer to vividness or to the absence of everyday content. In cases, though, Meares (1983a, p.118, 1987a, p.34, 1987/1991, p.114) juxtaposes the terms with drowsiness, which suggests that, at least in those passages, he is using them to refer to vividness.

The Shamatha meditator eliminates dullness through active, careful, and systematic efforts to arouse attention. The efforts to arouse attention in TM and Stillness Meditation are much more limited. In Stillness Meditation there is no effort to arouse attention, other than by maintaining a degree of discipline in the posture (see Woods et al. 2021). TM involves a degree of arousal in bringing attention to the mantra, but beyond that the emphasis is on abandoning any attempt to focus attention (see above).

These observations give the clear impression that TM and Stillness Meditation do not entirely eliminate dullness, and this leads to the understanding that the Shamatha goal-state involves substantially greater vividness. The vividness in TM and Stillness Meditation may be high according to standards from normal waking life, but the impression is that it is moderate or low in comparison to the perfect vividness in Shamatha.

The final feature of the goal-states for consideration in this section is attentional balance, which is a construct used only in the Shamatha accounts. The Shamatha goal-state is described as involving exceptional attentional balance in that "a high level of attentional arousal is maintained simultaneously with deep calm and relaxation" (Wallace 2012/2014, p.166). The TM and Stillness Meditation goal-states are said to involve deep calm and relaxation like in Shamatha, but they appear to involve considerably less attentional arousal. On this basis it seems that the attentional balance in the Shamatha goal-state is different to that in TM and Stillness Meditation.

14 Unless the meditator notices that they have lost awareness of the mantra. In that case they again bring their attention to it, to reinitiate the automatic movement (Woods et al. 2021). 
Table 16 Group 16 - Summary of Findings

\begin{tabular}{|c|c|c|c|}
\hline Feature of the goal-state/s & $\begin{array}{l}\text { Extraction table } \\
\text { section/s }\end{array}$ & Practices reported/implied in & $\begin{array}{l}\text { Are the goal-states the same or } \\
\text { different across the three practices } \\
\text { with respect to this feature? }\end{array}$ \\
\hline $\begin{array}{l}\text { Attention on the emptiness/ } \\
\text { silence (not everyday } \\
\text { content) }\end{array}$ & $\begin{array}{l}\text { SH 2.14.25 } \\
\text { TM 2.7.30 } \\
\text { SM 2.3.10 }\end{array}$ & All three practices & $\begin{array}{l}\text { Same, leaving aside the } \\
\text { nature/quality of the attention } \\
\text { (see rows below) }\end{array}$ \\
\hline Attentional stability & $\begin{array}{l}\text { SH } 2.14 .26 \\
\text { TM 2.7.22-2.7.23 } \\
\text { SM 2.3.16-2.3.17 }\end{array}$ & $\begin{array}{c}\text { Shamatha - perfect stability } \\
\text { TM and Stillness Meditation - } \\
\text { a degree of stability }\end{array}$ & $\begin{array}{l}\text { Different - substantially } \\
\text { greater in Shamatha } \\
\text { Unclear as between TM and } \\
\text { Stillness Meditation }\end{array}$ \\
\hline Attentional vividness & $\begin{array}{l}\text { SH 2.14.27 } \\
\text { TM 2.7.10 } \\
\text { SM 2.3.3 }\end{array}$ & $\begin{array}{l}\text { Shamatha - perfect vividness } \\
\text { TM and Stillness Meditation - } \\
\text { some/possible indications that } \\
\text { high degree of vividness }\end{array}$ & $\begin{array}{l}\text { Different - substantially } \\
\text { greater in Shamatha } \\
\text { Unclear as between TM and } \\
\text { Stillness Meditation }\end{array}$ \\
\hline Attentional balance & $\begin{array}{ll}\text { SH } & 2.14 .28 \\
\text { TM } 1.6,2.7 .12, & \\
& 2.7 .24,2.7 .29 \\
& 2.7 .30 \\
\text { SM } & 1.8,1.12,2.3 .8, \\
& 2.3 .10,2.3 .18 \\
& 2.3 .22\end{array}$ & $\begin{array}{l}\text { Shamatha - high degree of arousal } \\
\text { with deep calm and relaxation } \\
\text { TM and Stillness Meditation - } \\
\text { lower degree of arousal with } \\
\text { deep calm and relaxation }\end{array}$ & $\begin{array}{l}\text { Different in Shamatha } \\
\text { to TM and Stillness Meditation } \\
\text { Unclear as between TM and } \\
\text { Stillness Meditation }\end{array}$ \\
\hline
\end{tabular}

Note. With respect to Stillness Meditation, this table deals only with the deeper goal-states, where even very dull perceptions are absent.

\subsection{Group 17 - description in words is limited}

In each of the three practices the experts indicate that words are somehow limited in their ability to describe the goal-states. Pearson (2013, p.55) puts this particularly strongly, asserting that the TM goal-state/s are "fundamentally ineffable [or] indescribable", and "[u]tterly beyond words". McKinnon (2011, p.85) states that the Stillness Meditation goalstates are "far, far beyond words", and Meares (1978/1986, p.145) says that "[w]ords fail". Wallace (2018, p.58) expresses this by saying that "words take [the meditator] a step away from the experience". He says that words are a "conceptual overlay" on the experience (Wallace 2000, p.110), not the experience itself. The basic problem in the three practices seems to be that words typically involve or assume logic, concepts, and subject-object duality, but in this context they are called upon to describe the goal-states, which involve an absence of those qualities (e.g., Meares 1978/1986, p.20, 1989, p.113; Wallace 2000, p.110; McKinnon 2011, pp.85-86).

The limitation does not mean that nothing can be said about the goal-states. Indeed, the experts describe the goal-states in a great deal of detail, as is clear from this section 3 . As such, when the experts say that the experiences are beyond words, what they seem to mean is 
that some aspect is beyond words, or, equivalently, that the experiences are beyond words to some extent.

In each practice experts indicate that the gap between the words and the goal-states will be greater for someone who has not had the experience. A meditator who has had the experience will be able to draw on it in giving meaning to the words, and that will result in a reduction in the gap. Wallace indicates that for this reason the Shamatha goal-state is not regarded as ineffable, at least not for experienced meditators (Wallace 2007a, pp.79,82, 2011 b, p.179, 2018, p.57). Experienced meditators can discuss it with one another in terms that to them are clear and intelligible. The TM and Stillness Meditation experts do not make these points with respect to those practices. It seems hard to imagine, however, that they would argue against the idea that experienced meditators can discuss the goal-states in an intelligible fashion.

Table 17 Group 17 - Summary of Findings

\begin{tabular}{|c|c|c|c|}
\hline Feature of the goal-state/s & $\begin{array}{l}\text { Extraction table } \\
\text { section/s }\end{array}$ & Practices reported/implied in & $\begin{array}{l}\text { Are the goal-states the same or } \\
\text { different across the three practices } \\
\text { with respect to this feature? }\end{array}$ \\
\hline
\end{tabular}

\begin{tabular}{llll}
\hline To some extent cannot be & SH 2.1.1, 2.14.44 & All three practices & Unclear \\
described in words & TM 2.7.49 &
\end{tabular}

\subsection{Group 18 - variation within each practice}

Wallace generally presents the experience aimed for in Shamatha as a single state, rather than indicating any variation within it. It is the ground-state of consciousness or the mind, and is referred to as unfluctuating. There is, however, one strand of Wallace's analysis that suggests there could be variation in the experience. Wallace says that, although meditators do not consciously experience any concepts in the goal-state, certain implicit or subliminal conceptualization persists. In one text he notes that differences in meditators' implicit conceptualization can result in them having "significantly different" experiences of what appears on the surface to be a single state of pure consciousness (Wallace 2000, p.118). Although he does not make that statement with respect to the Shamatha goal-state specifically, he gives no reason to think that it would not apply in that context.

Wallace does not provide any further detail about how experiences may vary as the result of differences in implicit conceptualization. He explains that the meditator can reduce or eliminate the implicit conceptualization by way of certain other forms of meditation practice. Presumably a reduction in the implicit conceptualization could lead to a difference in the meditator's experience, but Wallace does not address this possibility explicitly. 
The TM experts often give the impression that the experience aimed for in TM is a single state. Shear does this most explicitly, by arguing in several publications that TM aims for pure consciousness, and that all experiences of pure consciousness are identical. Other experts give the same impression by stating or implying, for example, that TM aims for pure consciousness, that pure consciousness is the simplest and deepest state possible, that it is unfluctuating or non-changing, and that beginners have the same experience as experts.

In other places, however, the TM experts clearly refer to there being variation in the experience. Rosenthal indicates that there can be a high degree of variability, both between meditators and across sessions. He distinguishes between banal experiences of pure consciousness, such as a pleasant peace and stillness, and spectacular experiences, such as "[falling] into a pool of bliss" (Rosenthal 2016/2017, pp.33-39). He notes that Roth has commented that (in Rosenthal's words): “[M] any [TM meditators] rarely have experiences that can be readily identified as clear transcendence" (p.37). Pearson (2013, p.175) states that, with practice, experiences of pure consciousness become clearer and deeper. Roth (2018, p.96) says that his own experiences in TM have "continued to deepen" over his nearly 50 years of practice.

The experience aimed for in Stillness Meditation is generally presented as a range of goal-states. There are similarities in the way the range of goal-states in TM (where acknowledged) and the range in Stillness Meditation are characterized. As Rosenthal does for TM (see above), McKinnon indicates that there is a high level of variability in the Stillness Meditation goal-states, both between meditators and across sessions. Like the Pearson and Roth descriptions in TM, the Stillness Meditation goal-states are said to deepen as the meditator becomes more experienced.

In both TM and Stillness Meditation it appears that the deepening typically entails one or more of the other features of the goal-states becoming more pronounced. The meditator may report, for example, greater stillness, calm, clarity, simplicity, and/or naturalness. The accounts arguably also imply that certain features may at stages become less pronounced. In particular, if the deepest goal-state is somehow beyond stillness, calm and goodness/bliss, it seems that in some sense those features are less pronounced than in some of the preceding goal-states. 
Table 18 Group 18 - Summary of Findings

\begin{tabular}{|c|c|c|c|}
\hline Feature of the goal-state/s & $\begin{array}{l}\text { Extraction table } \\
\text { section/s }\end{array}$ & Practices reported/implied in & $\begin{array}{l}\text { Are the goal-states the same or } \\
\text { different across the three practices } \\
\text { with respect to this feature? }\end{array}$ \\
\hline $\begin{array}{l}\text { Variation in the experience } \\
\text { between meditators and } \\
\text { across sessions }\end{array}$ & $\begin{array}{cl}\text { SH } & 2.10,2.14 .42- \\
& 2.14 .43 \\
\text { TM } 1.5 .2,2.2, & \\
& 2.7 .47-2.7 .48 \\
\text { SM } 2.3 .36-2.3 .38\end{array}$ & All three practices & $\begin{array}{l}\text { Unclear, except in that the } \\
\text { shallower Stillness Meditation } \\
\text { goal-states can involve } \\
\text { very dull perceptions }\end{array}$ \\
\hline
\end{tabular}

\subsection{Summary of full set of findings}

The full set of findings is summarized in Table 19. 
Table 19 Summary of Full Set of Findings

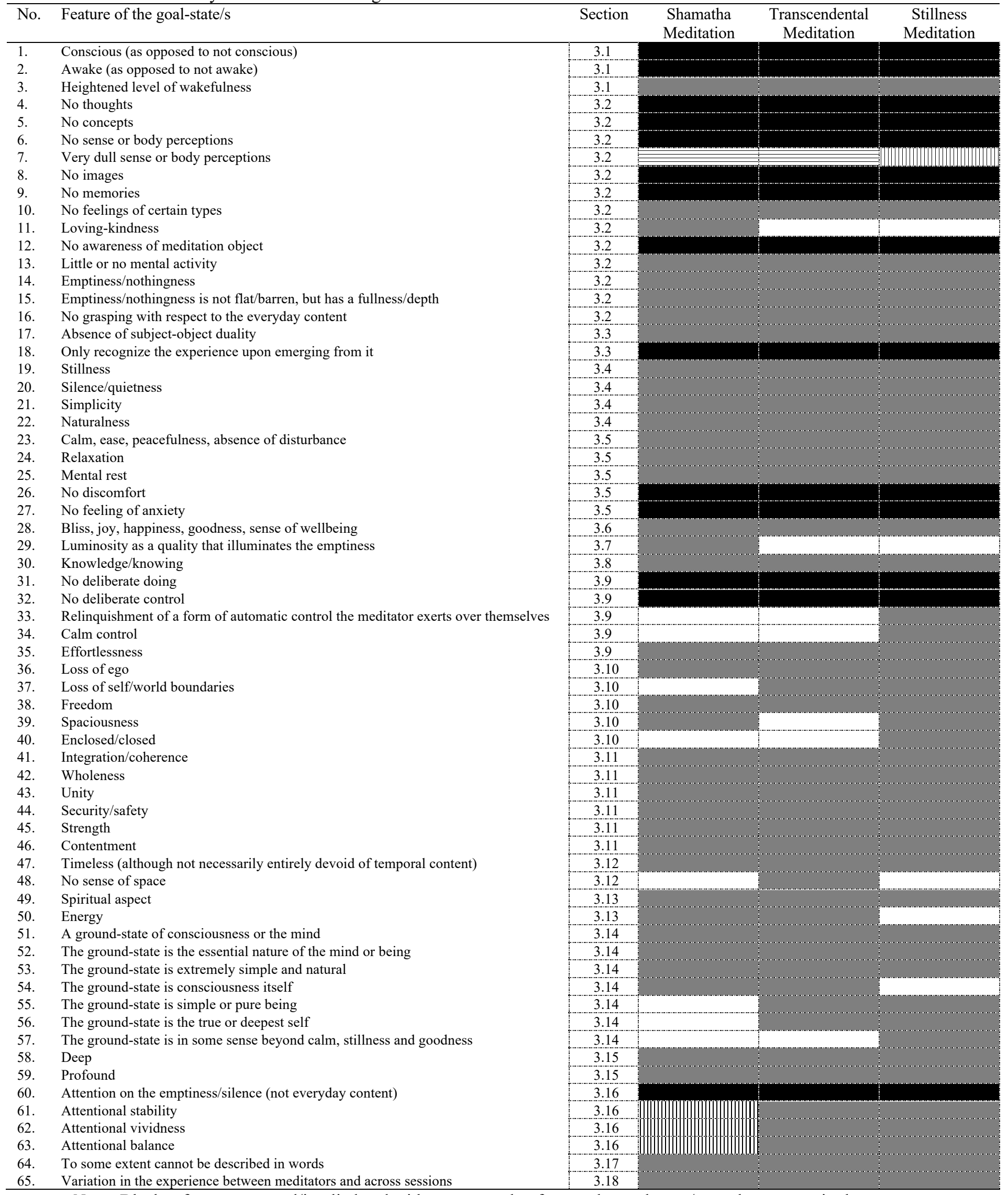

Note: Black = feature reported/implied and with respect to that feature the goal-state/s are the same as in the other two practices. Vertical cross-hatch $=$ feature reported/implied and with respect to that feature the goalstate/s are different to those in the other two practices. Grey $=$ feature reported/implied and with respect to that feature it is unclear whether the goal-state/s are the same or different to those in the other practice/s that are grey or white for that feature. White = feature not addressed (i.e., not reported/implied or ruled out). In those cases (white), with respect to that feature it is also unclear whether the goal-states are the same or different to those in the other practice/s that are grey or white for that feature. Horizontal cross-hatch $=$ feature ruled out. See Tables 1 to 18 for qualifications and additional detail with respect to each feature. 


\section{Discussion}

The findings were based on 135 Shamatha, TM and Stillness Meditation expert texts selected and reviewed using an evidence synthesis process. Through systematic extraction, coding, and analysis of the relevant passages in those texts, 65 experiential qualities were identified as features of the goal-states in one or more of the three practices. The goal-states were found to be the same across the practices with respect to 14 features and different with respect to four. For the remaining 47, it was unclear whether the goal-states are the same or different both across the three practices and any pairing of them.

\subsection{There is a broad similarity between the goal-states across the practices}

We found that 51 of the 65 features are reported or implied in all three traditions. That indicates a broad similarity between the goal-states across the practices. Of the remaining 14 features, six are reported or implied in only two practices, and eight in only one. ${ }^{15}$ Thirteen of those 14 features are not addressed in the remaining practice/s. ${ }^{16}$ It could be that they are present in those practice/s but just not referred to in the expert texts.

The fact that a feature is reported or implied in multiple practices does not mean that it is same (i.e., identical) in those practices. The features that we assessed to be the same in the three practices were as follows: The meditator is conscious (as opposed to not conscious), awake (as opposed to not awake), their attention is on the emptiness/silence (rather than it being on everyday content to any degree), and they only recognize the experience upon emerging from it (as opposed to recognizing it during the experience); they have no thoughts, concepts, perceptions, images, memories, discomfort, feelings of anxiety, or awareness of a meditation object; and there is no deliberate doing or deliberate control.

\subsection{There are differences between the goal-states across the practices}

The main difference between the goal-states across the practices identified from the expert texts is that the Shamatha goal-state involves greater attentional stability and vividness (section 3.16). In the Shamatha goal-state those qualities are reported to be "exceptional" or "perfect". Attention is so stable that it can remain on the emptiness/silence for four or more hours without the slightest deviation. In TM and Stillness Meditation, the meditator is said to move into and out of the goal-states repeatedly during a meditation session. That indicates a lower degree of attentional stability.

15 Note that these 14 features are different to the 14 referred to in the paragraph above.

16 The 14th feature is very dull sense or body perceptions. It is reported for the shallower goal-states in Stillness Meditation. It is effectively ruled out in Shamatha and TM, since in those practices all goalstates (not just the deeper ones) are reported to involve a complete absence of perceptions. 
The Shamatha goal-state is said to be so vivid that there is not even the slightest dullness. Dullness is eliminated in the interim-states, principally by arousing attention. The expert texts indicate that efforts to arouse attention in TM and Stillness Meditation are much more limited, and therefore give the clear impression that those practices do not entirely eliminate dullness. Some TM and Stillness Meditation goal-states may involve a high degree of vividness, but it appears that high degree is still lower than in Shamatha.

Another difference that we identified concerns what is described in the Shamatha texts as attentional balance (section 3.16). The Shamatha goal-state is said to involve exceptional attentional balance in that there is a high degree of attentional arousal together with deep calm and relaxation. That balance is treated as essential for achieving the exceptional stability and vividness (see also Woods et al. 2021). The TM and Stillness Meditation goal-states appear to involve a different attentional balance. The expert texts indicate that there is deep calm and relaxation, but less attentional arousal.

The final difference that we identified is that some Stillness Meditation goal-states involve very dull perceptions, whereas all Shamatha and TM goal-states involve none (section 3.2). This difference arises simply because Stillness Meditation defines what is being aimed for (i.e., the goal-states) slightly more broadly than Shamatha and TM. In all three practices, perceptions fade gradually as the meditator moves towards the goal-state/s. Shamatha and TM present what is being aimed for as the complete absence of perceptions. In Stillness Meditation it is the complete absence of perceptions, or perceptions that are only very dull. The shallower Stillness Meditation goal-states involve very dull perceptions, but the deeper goal-states involve none. The shallower goal-states therefore differ to the goalstates in Shamatha and TM.

As noted above, we found that for 47 features it is unclear whether the goal-states are the same or different across the practices. For example, it was not possible for us to determine whether the exact nature and level/degree of features such as wakefulness, stillness, calm, bliss/joy, and freedom is the same in each tradition. It could be that there are differences across the practices in addition to the four that we could identify.

\subsection{There is variation in the goal-states within each practice}

We found that there is variation in the goal-states within each practice (section 3.18). The Shamatha and TM experts often give the impression that within their respective practices there is a single goal-state, but in other places they report or imply that there can be variation in the experience between meditators and over time. The Stillness Meditation experts more 
consistently report such variation. In TM and Stillness Meditation clear examples of the variation are provided, whereas in Shamatha they are not.

The expert texts may specify a particular feature of the goal-state/s, but that does not necessarily mean that it is a feature of every goal-state in the practice. For example, each practice reports or implies that the goal-state, or the deepest goal-state, is a ground-state of consciousness or the mind, and we identified multiple features relating to the ground-states. Some TM and Stillness Meditation passages indicate that there can be goal-states that are not ground-states and that therefore do not have the ground-state features. Meditators might report, for example, having experienced a pleasant silence or stillness without thoughts, perceptions, or mental images, but not go so far as to say that it was a ground-state, consciousness itself, and the essential nature of their mind or being.

In each of the three practices, certain features are presented as being central or defining aspects of the goal-states. Examples are that the meditator is conscious and awake, there are no thoughts or mental images, there are no or virtually no perceptions, and there is subject-object nonduality, stillness and silence. Other features such as strength and contentment are described much less frequently.

Even for features that appear quite central, there can be disagreement between the experts in a practice. For example, most TM experts consider that the TM goal-state/s involve bliss and no perceptions or images. However, Shear argues in places that bliss is not part of the goal-state/s (section 3.6), and Rosenthal indicates that there may be vivid perceptions of the surrounding environment, and inner experiences of colours and lights (section 3.2).

\subsection{Contentless experiences can involve considerable variation}

In the academic literature, goal-states like those in Shamatha, TM and Stillness Meditation have been traditionally described as contentless experiences (Stace 1960/1961; Forman 1990b, 1998; Shear 2006d). The differences in the goal-states across and within the practices identified in this paper indicate that, if the goal-states are to be described as contentless experiences, contentless experiences are not all identical and in fact can involve considerable variation. This conclusion has important implications for consciousness, neuroscientific, and clinical research, and for basic understandings of the meditation practices.

In consciousness research it has been frequently claimed that all contentless experiences are identical (Almond 1982; Bucknell 1989a, b; Bernhardt 1990; Forman 1990a; Shear 1990b). If the goal-states are considered contentless experiences, our conclusion above 
challenges this understanding. Metzinger (2020a, p.38) has observed that descriptions of contentless experience have "common phenomenological denominators", but do not express "one single, unequivocal form of phenomenal character". ${ }^{17}$ Our systematic analysis of the expert texts provides empirical support for this understanding.

The conclusion that there is variation in contentless experiences should be taken into account in brain imaging studies. If imaging data relating to contentless experiences is being compared across individuals (engaged in different practices or the same practice), differences in those experiences need to be considered. Future research may require more nuanced selfreporting of contentless experiences in order to map specific types of contentless experience to the associated neural processes.

The conclusion also raises the question of whether there might be different clinical outcomes from different types of contentless experience - for example, experiences with single-pointed attention (Shamatha) and those without it (TM and Stillness Meditation). The differences in experience are also a further consideration that clinicians should take into account when recommending practices for clinical purposes.

Recognizing the variation in contentless experience helps to understand the meditation practices at a basic level. For instance, our analysis of the expert texts suggests it is much quicker and easier to access the goal-states in TM and Stillness Meditation than the goal-state in Shamatha (Woods et al. 2021). If the Shamatha goal-state involves greater stability and vividness, this difference in speed and ease makes sense.

Future research could test the descriptions of contentless experience in the expert texts using participant-based methods such as microphenomenology (see, e.g., Przyrembel and Singer 2018; Petitmengin et al. 2019). It could also investigate the techniques and mechanisms that lead to the experience, and which aspects are responsible for differences in the experience across the practices.

Another important project would be to systematically examine similarities and differences between the goal-states that we have explored and those in other practices. For example, a common tendency in academic research has been to treat as equivalent, or focus only on similarities between, the TM goal-state and enlightenment state/s in Buddhist practices, referred to as pristine awareness, nondual awareness, or buddha nature (e.g., Nash and Newberg 2013; Berman and Stevens 2015; Metzinger 2018; Reddy and Roy 2019).

17 Specifically, Metzinger says that paradigmatic descriptions of pure consciousness experiences have strong common phenomenological denominators. He makes clear that pure consciousness experiences might also be described as contentless. 
Other work has suggested there may be substantial differences (Studstill 2005; Austin 2006; Josipovic and Miskovic 2020). Comparison between the states using a form of evidence synthesis similar to the one that we have developed would provide a much better understanding of which features are shared and which are not.

\subsection{Some contentless experiences are not truly contentless}

The traditional understanding in the academic literature has been that contentless experiences lack all content, or at least all content other than being conscious and wakeful (Stace 1960/1961; Forman 1990b, 1999; Shear 1990b). In response to this traditional view, other scholars have argued that experiences said to be contentless may in fact involve subtle and abstract forms of content (e.g., Wainright 1981; Katz 1985; Barbiero 1993; Sullivan 1995; Shear 1998/1999, 2002, 2007; Gennaro 2008; Kwan 2009; Metzinger 2020a). In general these accounts provide little detail as to the specific forms of content that may be present, and do not compare the presence of such content across a range of practices said to access contentless experience. ${ }^{18}$

Our analysis adds to these accounts by identifying in a comprehensive and systematic manner the types of content experts indicate are present in the Shamatha, TM and Stillness Meditation goal-states. We have found that many forms of content are reported/implied as present in all three practices. These include wakefulness, emptiness, stillness, silence, simplicity, naturalness, calm, relaxation, rest, bliss/joy, knowledge/knowing, freedom, wholeness, security, unity, depth, and profundity. In TM and Stillness Meditation there is some evidence that the deepest goal-states may be in some sense beyond certain of these qualities (sections 2.2 and 3.14), but that evidence is quite limited and it is not clear how it fits with the many other passages indicating presence of that content.

The key implication of these findings is that, if contentless experiences are taken to include goal-states like those in Shamatha, TM and Stillness Meditation, some contentless experiences are not truly contentless. The contentless experiences in those practices are contentless in the limited sense that they lack well recognized forms of content such as thoughts, perceptions, and mental images. ${ }^{19}$ However, the preponderance of evidence indicates they are not contentless in the more complete sense of lacking all forms of content, or all forms of content other than being conscious and wakeful. The findings indicate that in

\footnotetext{
18 Metzinger (2020) is a notable exception in that he discusses the content in some depth.

19 Consistent with this, it has been noted that pure consciousness may lack "obvious", "usual", "gross", "ordinary", or "typical” content (Gennaro 2008, p.12; Strawson 2013, p.19; Harris 2018, 1:23:19; Millière et al. 2018, p.15; see also Studstill 2005, p.22).
} 
many and perhaps most cases where meditation states are described as contentless in the academic and traditional literatures, those states are not truly contentless. It will be interesting for future studies to determine whether there are experiences in other practices that are contentless in a more complete sense than those examined here.

\subsection{Meditators report ego dissolution and discovery of the true or deepest self}

In cognitive science and philosophy, ego is commonly treated as equivalent to sense of self (Millière 2017; Millière et al. 2018). Millière et al. (2018) note that a person's ordinary sense of self has multiple dimensions or components (see also Millière and Metzinger 2020a; Millière 2020). Loss of ego involves reduction in sense of self on one or more of the dimensions. It can therefore take different forms, depending on the dimensions for which the reduction occurs and the degree of reduction on each. A distinction can be drawn between partially selfless and totally selfless experiences (Millière 2020). The latter are defined as lacking all forms of self-related content.

Millière et al. (2018) identify as important dimensions of self, the self-experience derived from self-related thoughts and beliefs, autobiographical memories, body awareness, and spatial location. The last of these is referred to as spatial self-location. It is the experience of self as "distinct from and located at a precise point within the world" (Windt 2015, p.16). Loss of spatial self-location is understood to correspond to the loss of self/world boundaries (Windt 2015; Millière et al. 2018).

The Shamatha, TM and Stillness Meditation experts indicate that there is a dissolution of ego in the goal-states (section 3.10). We have captured this principally via the overarching feature "Loss of ego", but several of the other features that we have identified indicate loss of specific dimensions of ego/self. The features no thoughts, no concepts, no memories, no sense or body perceptions, and loss of self/world boundaries imply loss of the four dimensions of self identified by Millière et al. (2018). Loss of self/world boundaries is explicitly reported in TM and Stillness Meditation, and the other features are reported/implied in all three practices.

Our analysis also indicates the loss of other kinds of self-experience, most notably the sense of self as subject experiencing various objects (subject-object duality) and the sense of self that derives from the exercise of control. Loss of these forms of self-experience is reported/implied in each practice, but it is unclear whether what is being described is identical.

While the expert texts indicate that sense of self is extinguished on many dimensions, there is evidence that the TM and Stillness Meditation ground-states may not be 
totally selfless. In those practices, meditators sometimes report that in the ground-state they experience their true or deepest self (section 3.14; cf. Metzinger 2020b, 1:06:18). In all three practices the ground-state is said to be the essential nature of the mind or being, but the expert texts do not address whether Shamatha meditators may also describe that as their true or deepest self.

\subsection{The findings suggest that $\mathrm{TM}$ is not jhana practice}

Among meditation experts who have practised TM, differing views have been put forward as to whether TM is a jhana practice. Jhana practices are concentrative techniques in which meditators aim to reach and advance through the meditative absorptions (Austin 2006; Vago and Zeidan 2016). The absorptions include the final state aimed for in Shamatha, and a series of eight further states (Sanskrit: dhyana; Pali: jhana) that are progressively deeper and more refined (SH2.2; Wallace 2006a; Braun 2015). ${ }^{20}$ In this context, the state aimed for in Shamatha is often referred to as access concentration, and is said to lie on the threshold of the deeper - or full - absorptions (Goleman 1988; Wallace 2012/2014). The absorptions involve single-pointed or extremely focused attention (Austin 2006; Brahm 2006/2014).

Goleman (1988, p.67) has argued that TM is a "mainstream" jhana practice. He indicates that the TM goal-state is access concentration or one of the deeper absorptions, and both he and Forman (1999) consider that TM achieves single-pointed attention. Rosenthal (2016/2017), in contrast, reports absorption expert Leigh Brasington's view that the TM goalstate does not align with any of the jhanas (see also Austin 2006).

Our finding is that, based on the expert descriptions in the extraction tables, the TM goal-state does not involve single-pointed or extremely focused attention (section 3.16; see also Woods et al. 2021). The TM meditator's attention appears to move from the emptiness/silence to everyday content multiple times during a meditation session. Our finding therefore supports the view that TM is not a jhana practice.

\subsection{The finding "Unclear" reflects a strength of our approach}

As mentioned, for 47 features our assessment was that it is unclear whether the goalstates are identical or different across the practices. The finding "Unclear", and the detail that emerges concerning the ambiguity, reflect a strength of our approach. This can be illustrated using the ground-state features. The detailed, structured approach used in this paper allows us to see that there are multiple features relating to the ground-states, and that it is unclear

20 In some sources only the first four of the eight further states are referred to as "jhanas". For example, Brahm (2006/2014) usually describes the second four as "immaterial attainments". 
whether they are the same or different across the practices. It also provides rich detail concerning the nature of each feature and the reasons for the ambiguity. This leads to new research questions. For example, do the ground-state/s represent all of the goal-states in a particular practice, or just a subset of them? Does the relevant tradition consider that deeper ground-states can be attained in other practices? Is the ground-state in a practice merely the deepest state possible for each individual person, meaning that the ground-state/s can vary across meditators? Does the meditator always have the same experience of the ground-state, or can there be variation across time?

\subsection{Limitations}

This paper has used a scientific framework - evidence synthesis - to understand how the Shamatha, TM and Stillness Meditation goal-states are described in the three traditions. Limitations of evidence synthesis in this context have been discussed at some length in Woods et al. (2020). A key limitation is that the experts have outstanding qualifications in terms of their traditional knowledge, but that is not the same as having the skills in science or phenomenology that may be necessary to provide or obtain reliable reports of experience. For example, experts in phenomenology and first-person methods have techniques to focus the person providing the report on a specific experience at a particular point in time, as it is understood that this improves reliability (Hurlburt and Schwitzgebel 2007; Overgaard et al. 2008; Lumma and Weger 2021). Some of the descriptions in the expert texts relate to a specific experience while others are more generalized.

As a separate point, we do not claim that the set of goal-state features identified in this paper is definitive, but rather that it can be clearly justified. We acknowledge that there may be alternative feature-sets that are also reasonable. Other researchers might choose to split certain features into narrower types, or they might combine features on the basis of overlaps. We would expect them to identify the same broad similarities and/or differences in a comparison across the practices, but their final set of features (which those similarities and/or differences map on to) might be different.

A further possible criticism of this paper is that the first author (TW), who has practised Stillness Meditation for over 20 years, has greater familiarity with that practice than with Shamatha or TM. While this differing familiarity could have influenced the analysis, we consider that any such impact would be minimal. The analysis was based on the extraction tables, not TW's personal experience with the practices. Those tables and the method for the evidence synthesis have each been made available (see Woods et al. 2020 and Online Resource 2), to provide full transparency. Samples of TW's decision-making were 
independently assessed by the third author (OC). Neither OC nor JW have any personal history with the three practices.

\subsection{Conclusion}

The detailed and systematic approach taken in this paper has demonstrated the multidimensional nature of contentless experience in Shamatha, TM and Stillness Meditation. Based on the expert texts, we have determined that there are broad similarities between the experiences across the traditions, but that there are also differences both across and within the practices. Another key finding is that, while various forms of content are said to be absent in the experiences, numerous other forms are referred to as being present.

The findings indicate that meditation experiences described as contentless in the academic literature can in fact involve considerable variation, and that often these experiences are not truly contentless. This challenges traditional understandings in academic research that in contentless experiences all content is absent, and that the experiences are therefore an identical state of pure consciousness or consciousness itself. Our analysis has important implications for neuroscientific and clinical research, and lays the groundwork for further explorations of contentless experience using diverse methodologies.

\section{References}

Almond, P. C. (1982). Mystical experience and religious doctrine: An investigation of the study of mysticism in world religions. Berlin, Germany: Mouton.

Arenander, A., \& Travis, F. (2004). Brain patterns of self-awareness. In B. Beitman \& J. Nair (Eds.), Deficits of self-awareness in psychiatric disorders (pp. 112-126). New York, NY: Norton.

Austin, J. H. (2006). Zen-brain reflections: Reviewing recent developments in meditation and states of consciousness. Cambridge, MA: MIT Press.

Barbiero, D. (1993). Review of the book "The problem of pure consciousness", by R. K. C. Forman. Philosophy East and West, 43(4), 766-769.

Berman, A. E., \& Stevens, L. (2015). EEG manifestations of nondual experiences in meditators. Consciousness and Cognition, 31, 1-11. https://doi.org/10.1016/j.concog.2014.10.002

Bernhardt, S. (1990). Are pure consciousness events unmediated? In R. K. C. Forman (Ed.), The problem of pure consciousness: Mysticism and philosophy (pp. 220-236). New York, NY: Oxford University Press.

Bitbol, M., \& Petitmengin, C. (2013). A defense of introspection from within. Constructivist Foundations, 8(3), 269-279. 
Brahm, A. (2006/2014). Mindfulness, bliss, and beyond: A meditator's handbook. Somerville, MA: Wisdom.

Braun, E. (2015). The United States of jhana: Varieties of modern Buddhism in America. In S. A. Mitchell \& N. E. F. Quli (Eds.), Buddhism beyond borders: New perspectives on Buddhism in the United States (pp. 163-180). Albany, NY: SUNY Press.

Bucknell, R. S. (1989a). Buddhist jhana as mystical experience. In G. K. Zollschan, J. F. Schumaker, \& G. F. Walsh (Eds.), Exploring the paranormal: Perspectives on belief and experience (pp. 131-149). Dorset, United Kingdom: PRISM Press.

Bucknell, R. S. (1989b). Buddhist meditation and the study of mystical experience. Charles Strong Memorial Lecture. 14th Annual Conference of The Australian Association for the Study of Religions, Perth, Australia.

Christoff, K., Irving, Z. C., Fox, K. C., Spreng, R. N., \& Andrews-Hanna, J. R. (2016). Mindwandering as spontaneous thought: A dynamic framework. Nature Reviews Neuroscience, 17(11), 718-731. https://doi.org/10.1038/nrn.2016.113

Costines, C., Borghardt, T. L., \& Wittmann, M. (2021). The phenomenology of "pure" consciousness as reported by an experienced meditator of the Tibetan Buddhist Karma Kagyu tradition. Analysis of interview content concerning different meditative states. Philosophies, 6(50), 1-22. https://doi.org/10.3390/philosophies6020050

Dainton, B. (2000). Stream of consciousness: Unity and continuity in conscious experience. London, United Kingdom: Routledge.

Dainton, B. (2002). The gaze of consciousness. Journal of Consciousness Studies, 9(2), 3148.

Faber, P. L., Travis, F., Milz, P., \& Parim, N. (2017). EEG microstates during different phases of Transcendental Meditation practice. Cognitive Processing, 18, 307-314. https://doi.org/10.1007/s10339-017-0812-y

Forman, R. K. C. (1990a). Introduction: Mysticism, constructivism, and forgetting. In R. K. C. Forman (Ed.), The problem of pure consciousness: Mysticism and philosophy (pp. 3-49). New York, NY: Oxford University Press.

Forman, R. K. C. (Ed.) (1990b). The problem of pure consciousness: Mysticism and philosophy. New York, NY: Oxford University Press.

Forman, R. K. C. (1998). What does mysticism have to teach us about consciousness? Journal of Consciousness Studies, 5(2), 185-201.

Forman, R. K. C. (1999). Mysticism mind consciousness. Albany, NY: SUNY Press.

Gamma, A., \& Metzinger, T. (2021). The Minimal Phenomenal Experience questionnaire (MPE-92M): Towards a phenomenological profile of "pure awareness" experiences in meditators. PLoS One, 16(7), 1-39. https://doi.org/10.1371/journal.pone.0253694

Gellman, J. (2018). Mysticism. In E. N. Zalta (Ed.), The Stanford encyclopedia of philosophy (Fall 2018 ed.). Stanford University. https://plato.stanford.edu/entries/mysticism/ 
Gennaro, R. J. (2008). Are there pure consciousness events? In C. Chakrabarti \& G. Haist (Eds.), Revisitng mysticism (pp. 100-120). Newcastle, United Kingdom: Cambridge Scholars.

Gimello, R. M. (1978). Mysticism and meditation. In S. T. Katz (Ed.), Mysticism and philosophical analysis (pp. 170-199). New York, NY: Oxford University Press.

Goleman, D. (1988). The meditative mind: The varieties of meditative experience. New York, NY: Target/Putnam.

Harris, S. (Host) (2018). Consciousness and the self (No. 113). Podcast episode In Making Sense series. https://samharris.org/podcasts/113-consciousness-and-the-self/

Hosemans, D. J. F. (2017). Equanimity and the attentuation of psychological distress. Doctoral dissertation. Monash University, Melbourne, Australia.

Hurlburt, R. T., \& Schwitzgebel, E. (2007). Describing inner experience? Proponent meets skeptic. Cambridge, MA: MIT Press.

Jacobs, T. L., Epel, E. S., Lin, J., Blackburn, E. H., Wolkowitz, O. M., Bridwell, D. A., Zanesco, A. P., Aichele, S. R., Sahdra, B. K., MacLean, K. A., King, B. G., Shaver, P. R., Rosenberg, E. L., Ferrer, E., Wallace, B. A., \& Saron, C. D. (2011). Intensive meditation training, immune cell telomerase activity, and psychological mediators. Psychoneuroendocrinology, 36(5), 664-681. https://doi.org/10.1016/j.psyneuen.2010.09.010

Jones, R. H. (1993). Mysticism examined: Philosophical inquiries into mysticism. Albany, NY: SUNY Press.

Josipovic, Z., \& Miskovic, V. (2020). Nondual awareness and minimal phenomenal exeprience. Frontiers in Psychology, 11, 1-9. https://doi.org/10.3389/fpsyg.2020.02087

Katz, S. T. (1985). Recent work on mysticism. History of Religions, 25(1), 76-86.

Kwan, K. (2009). The argument from religious experience. In W. L. Craig \& J. P. Moreland (Eds.), The Blackwell companion to natural theology (pp. 498-552). West Sussex, United Kingdom: Wiley-Blackwell.

Lancaster, B. L. (2004). Approaches to consciousness: The marriage of science and mysticism. Hampshire, United Kingdom: Palgrave Macmillan.

Lati Rinbochay \& Denma Lochö Rinbochay (1983/1997). Meditative states in Tibetan Buddhism. Somerville, MA: Wisdom.

Lumma, A. \& Weger, U. (2021). Looking from within: Comparing first-person approaches to studying experience. Current Psychology. Online publication. https://doi.org/10.1007/s12144-021-02277-3

Lutz, A., Dunne, J. D., \& Davidson, R. J. (2007). Meditation and the neuroscience of consciousness: An introduction. In P. D. Zelazo, M. Moscovitch, \& E. Thompson 
(Eds.), The Cambridge handbook of consciousness (pp. 499-551). New York, NY: Cambridge University Press.

Maharishi Mahesh Yogi (1967/1974). Maharishi Mahesh Yogi on the Bhagavad-Gita: A new translation and commentary with Sanskrit text-chapters 1 to 6. Middlesex, United Kingdom: Penguin.

Maharishi Mahesh Yogi (1963/2001). Science of being and art of living: Transcendental Meditation (Rev. ed.). New York, NY: Penguin.

Markovic, J. \& Thompson, E. (2016). Hypnosis and meditation: A neurophenomenological comparison. In A. Raz \& M. Lifshitz (Eds.), Hypnosis and meditation: Towards an integrative science of conscious planes (pp. 79-106). Oxford, United Kingdom: Oxford University Press.

McKinnon, P. (2002/2008). Let's be still: Teaching Stillness Meditation to children and adolescents. Melbourne, Australia: David Lovell.

McKinnon, P. (2011). Living calm in a busy world: Stillness Meditation in the Meares tradition. Melbourne, Australia: David Lovell.

McKinnon, P. (1983/2016). In stillness conquer fear: How to break free from anxiety and phobias (Rev. ed.). Melbourne, Australia: Garratt.

Meares, A. (1967b). Psychological control of organically determined pain. Annals of the Australian College of Dental Surgeons, 1, 42-46.

Meares, A. (1967/1968). Relief without drugs: The self-management of tension, anxiety, and pain. London, United Kingdom: Souvenir Press.

Meares, A. (1969c). Student problems and a guide to study. Melbourne, Australia: Hawthorn Press.

Meares, A. (1971a). Group relaxing hypnosis. The Medical Journal of Australia, 2(13), 675676.

Meares, A. (1973a). A psychiatric experiment in community service. The Medical Journal of Australia, 15(4), 733-734. https://doi.org/10.5694/j.1326-5377.1973.tb110661.x

Meares, A. (1979b). Dialogue on meditation. Melbourne, Australia: Hill of Content.

Meares, A. (1976/1980). Let's be human: New reactions for old. Melbourne, Australia: Hill of Content.

Meares, A. (1980e). Thoughts. Melbourne, Australia: Hill of Content.

Meares, A. (1983a). A form of intensive meditation associated with the regression of cancer. American Journal of Clinical Hypnosis, 25(2-3), 114-121. https://doi.org/10.1080/00029157.1982.10404082

Meares, A. (1984). A way of doctoring. Melbourne, Australia: Hill of Content. 
Meares, A. (1976/1984). From the quiet place. Melbourne, Australia: Hill of Content.

Meares, A. (1978/1986). The wealth within: Self-help through a system of relaxing meditation. Melbourne, Australia: Hill of Content.

Meares, A. (1987a). Let's be at ease. Melbourne, Australia: Greenhouse.

Meares, A. (1989). A better life: The guide to meditation. Melbourne, Australia: Greenhouse.

Meares, A. (1987/1991). Life without stress: The self-management of stress. Melbourne, Australia: Penguin.

Metzinger, T. (2018). Lecture 3: Minimal phenomenal experience. Rudolf-Carnap-Lectures. Ruhr-Universität, Bochum, Germany. https://www.youtube.com/watch?v=Er8DM5AW3IM

Metzinger, T. (2020a). Minimal phenomenal experience: Meditation, tonic alertness, and the phenomenology of "pure" consciousness. Philosophy and the Mind Sciences, 1(1), 144. https://doi.org/10.33735/phimisci.2020.I.46

Metzinger, T. (2020b). Minimal phenomenal experience: Towards a minimal-model explanation for consciousness as "as such." Mathematical Consciousness Science online seminar series. https://www.youtube.com/watch?v=zc7xwBZC9Hc

Millière, R. (2017). Looking for the self: Phenomenology, neurophysiology and philosophical significance of drug-induced ego dissolution. Frontiers in Human Neuroscience, 11, 1-22. https://doi.org/10.3389/fnhum.2017.00245

Millière, R. (2020). The varieties of selflessness. Philosophy and the Mind Sciences, 1(I), 141. https://doi.org/10.33735/phimisci.2020.I.48

Millière, R., Carhart-Harris, R. L., Roseman, L., Trautwein, F. M., \& Berkovich-Ohana, A. (2018). Psychedelics, meditation, and self-consciousness. Frontiers in Psychology, 9 , 1-29. https://doi.org/10.3389/fpsyg.2018.01475

Nash, J. D. \& Newberg, A. (2013). Toward a unifying taxonomy and definition for meditation. Frontiers in Psychology, 4, 1-18. https://doi.org/10.3389/fpsyg.2013.00806

Overgaard, M., Gallagher, S., \& Ramsøy, T. Z. (2008). An integration of first-person methodologies in cognitive science. Journal of Consciousness Studies, 15(8), 100120.

Pearson, C. (2013). The supreme awakening: Experiences of enlightenment throughout timeand how you can cultivate them. Fairfield, IA: Maharishi University of Management Press.

Petitmengin, C., van Beek, M., Bitbol, M., Nissou, J. M., \& Roepstorff, A. (2019). Studying the experience of meditation through micro-phenomenology. Current Opinion in Psychology, 28, 54-59. https://doi.org/10.1016/j.copsyc.2018.10.009 
Przyrembel, M., \& Singer, T. (2018). Experiencing meditation - Evidence for differential effects of three contemplative mental practices in micro-phenomenological interviews. Consciousness and Cognition, 62, 82-101. https://doi.org/10.1016/j.concog.2018.04.004

Reddy, J., \& Roy, S. (2019). Understanding meditation based on the subjective experience and traditional goal: Implications for current meditation research. Frontiers in Psychology, 10, 1-9. https://doi.org/10.3389/fpsyg.2019.01827

Rigato, J., Rennie, S. M., \& Mainen, Z. F. (2021). The overlooked ubiquity of first-person experience in the cognitive sciences. Synthese, 198(9), 8005-8041. https://doi.org/10.1007/s11229-019-02136-6

Rosenberg, E. L., Zanesco, A. P., King, B. G., Aichele, S. R., Jacobs, T. L., Bridwell, D. A., MacLean, K. A., Shaver, P. R., Ferrer, E., Sahdra, B. K., Lavy, S., Wallace, B. A., \& Saron, C. D. (2015). Intensive meditation training influences emotional responses to suffering. Emotion, 15(6), 775-790. https://doi.org/10.1037/emo0000080

Rosenthal, N. E. (2011/2012). Transcendence: Healing and transformation through Transcendental Meditation. New York, NY: Penguin.

Rosenthal, N. E. (2016/2017). Super Mind: How to boost performance and live a richer and happier life through Transcendental Meditation. New York, NY: Penguin.

Roth, B. (2018). Strength in stillness: The power of Transcendental Meditation. London, United Kingdom: Simon \& Schuster.

Schwitzgebel, E. (2008). The unreliability of naive introspection. Philosophical Review, 117(2), 245-273. https://doi.org/doi.org/10.1215/00318108-2007-037

Seymour, M. (1999). The teacher's role and the student's experience in Ainslie Meares' approach to Stillness Meditation: Moving beyond technique to create an environment of trust. Unpublished master's thesis. La Trobe University, Melbourne, Australia.

Shear, J. (1990a). Mystical experience, hermeneutics, and rationality. International Philosophical Quarterly, 30(4), 391-401. https://doi.org/10.5840/ipq199030436

Shear, J. (1990b). The inner dimension: Philosophy and the experience of consciousness (2nd ed.). London, United Kingdom: Harmonia.

Shear, J. (1995/1997b). The hard problem: Closing the empirical gap. In J. Shear (Ed.), Explaining consciousness - The "hard" problem (pp. 359-375). Cambridge, MA: MIT Press.

Shear, J. (1998/1999). Experiential clarification of the problem of self. In S. Gallagher \& J. Shear (Eds.). Models of the self (pp. 407-420). Devon, United Kingdom: Imprint.

Shear, J. (2002). Ethics and the experience of happiness. In G. W. Barnard \& J. J. Kripal (Eds.), Crossing boundaries: Essays on the ethical status of mysticism (pp. 361-380). New York, NY: Seven Bridges Press. 
Shear, J. (2006b). Introduction. In J. Shear (Ed.), The experience of meditation: Experts introduce the major traditions (pp. xiii-xxii). St. Paul, MN: Paragon House.

Shear, J. (Ed.). (2006d). The experience of meditation: Experts introduce the major traditions. St. Paul, MN: Paragon House.

Shear, J. (2007). Eastern methods of investigating mind and consciousness. In M. Velmans \& S. Schneider (Eds.), The Blackwell companion to consciousness (pp. 697-710). Malden, MA: Blackwell.

Shear, J. (2011a). Eastern approaches to altered states of consciousness. In E. Cardeña \& M. Winkelman (Eds.), Altering consciousness: Multidisciplinary perspectives (Vol. 1, pp. 139-158). Santa Barbara, CA: Praeger.

Shear, J. (2014a). Meditation as first-person methodology: Real promise-and problems. In S. Schmidt \& H. Walach (Eds.), Meditation - Neuroscientific approaches and philosophical implications (pp. 57-74). Cham, Switzerland: Springer International.

Shear, J. (2014b). Some reflections on meditation research and consciousness studies. Journal of Consciousness Studies, 21(3-4), 202-215.

Shear, J. \& Jevning, R. (1999a). Pure consciousness: Scientific exploration of meditation techniques. Journal of Consciousness Studies, 6(2-3), 189-210.

Stace, W. T. (1960/1961). Mysticism and philosophy. London, United Kingdom: Macmillan.

Strawson, G. (2015). Self-intimation. Phenomenology and the Cognitive Sciences, 14(1), 1-31. https://doi.org/10.1093/acprof:oso/9780198777885.003.0008

Studstill, R. (2005). Unity of mystical traditions: The transformation of consciousness in Tibetan and German mysticism. Leiden, The Netherlands: Brill.

Sullivan, P. R. (1995). Contentless consciousness and information-processing theories of mind. Psychiatry \& Psychology, 2(1), 51-59.

Thompson, E. (2006/2008). Neurophenomenology and contemplative experience. In P. Clayton \& Z. Simpson (Eds.), The Oxford handbook of religion and science (pp. 226235). Oxford, United Kingdom: Oxford University Press.

Thompson, E. (2015). Dreamless sleep, the embodied mind, and consciousness: The relevance of a classical Indian debate to cognitive science. In T. Metzinger \& J. M. Windt (Eds.), Open MIND (Vol. 37, pp. 1-19). Frankfurt am Main, Germany: MIND Group.

Tong, A., Flemming, K., McInnes, E., Oliver, S., \& Craig, J. (2012). Enhancing transparency in reporting the synthesis of qualitative research: ENTREQ. BMC Medical Research Methodology, 12(181), 1-8. https://doi.org/10.1186/1471-2288-12-181

Travis, F. (2011). States of consciousness beyond waking, dreaming and sleeping: Perspectives from research on meditation experiences. In D. Cvetkovic \& I. Cosic (Eds.), States of consciousness: Experimental insights into meditation, waking, sleep and dreams (pp. 223-234). Berlin, Germany: Springer. 
Travis, F., Munly, K., Olson, T. M., \& Sorflaten, J. W. (2005). Maharishi Vedic science addresses the "hard" problem of consciousness. Journal of Social Behavior and Personality, 17(1), 123-135.

Vago, D. R., \& Zeidan, F. (2016). The brain on silent: Mind wandering, mindful awareness, and states of mental tranquility. Annals of the New York Academy of Sciences, 1373(1), 96-113. https://doi.org/10.1111/nyas.13171

Vieten, C., Wahbeh, H., Cahn, B. R., MacLean, K., Estrada, M., Mills, P., Murphy, M., Shapiro, S., Radin, D., Josipovic, Z., Presti, D., Sapiro, M., Bays, J. C., Russell, P., Vago, D., Travis, F., Walsh, R., \& Delorme, A. (2018). Future directions in meditation research: Recommendations for expanding the field of contemplative science. PloS One, 13(11), 1-30. https://doi.org/10.1371/journal.pone.0205740

Wainright, W. J. (1981). Mysticism: A study of its nature, cognitive value and moral implications. Sussex, United Kingdom: Harvester Press.

Wallace, B. A. (1999b). Training the attention and exploring consciousness in Tibetan Buddhism. In S. R. Hameroff, A. W. Kaszniak, \& D. J. Chalmers (Eds.), Toward a science of consciousness III: The third Tucson discussions and debates (pp. 441-448). Cambridge, MA: MIT Press.

Wallace, B. A. (2000). The taboo of subjectivity. Toward a new science of consciousness. Oxford, United Kingdom: Oxford University Press.

Wallace, B. A. (2001a). Intersubjectivity in Indo-Tibetan Buddhism. Journal of Consciousness Studies, 8(5-6), 209-230.

Wallace, B. A. (2001/2003). Buddhism with an attitude: The Tibetan seven-point mindtraining. Ithaca, NY: Snow Lion.

Wallace, B. A. (1989/2003). Choosing reality: A Buddhist view of physics and the mind. Ithaca, NY: Snow Lion.

Wallace, B. A. (2005). Genuine happiness: Meditation as the path to fulfillment. Hoboken, NJ: John Wiley.

Wallace, B. A. (1998/2005). Balancing the mind: A Tibetan Buddhist approach to refining attention. Boston, MA: Shambhala.

Wallace, B. A. (2006a). The attention revolution: Unlocking the power of the focused mind. Somerville, MA: Wisdom.

Wallace, B. A. (2007a). Contemplative science: Where Buddhism and neuroscience converge. New York, NY: Columbia University Press.

Wallace, B. A. (2007b). Hidden dimensions: The unification of physics and consciousness. New York, NY: Columbia University Press.

Wallace, B. A. (2010). The four immeasurables: Practices to open the heart (3rd ed.). Ithaca, NY: Snow Lion. 
Wallace, B. A. (2011a). Minding closely: The four applications of mindfulness. Ithaca, NY: Snow Lion.

Wallace, B. A. (2011b). Stilling the mind: Shamatha teachings from Düdjom Lingpa's Vajra Essence. Somerville, MA: Wisdom.

Wallace, B. A. (2012). Dreaming yourself awake: Lucid dreaming and Tibetan dream yoga for insight and transformation. Boston, MA: Shambhala.

Wallace, B. A. (2012/2014). Meditations of a Buddhist skeptic: A manifesto for the mind sciences and contemplative practice. New York, NY: Columbia University Press.

Wallace, B. A. (2009/2014). Mind in the balance: Meditation in science, Buddhism, and Christianity. New York, NY: Columbia University Press.

Wallace, B. A. (2018). Fathoming the mind: Inquiry and insight in Düdjom Lingpa's Vajra Essence. Somerville, MA: Wisdom.

Wallace, B. A., \& Hodel, B. (2008). Embracing mind: The common ground of science \& spirituality. Boston, MA: Shambhala.

Windt, J. M. (2015). Just in time - Dreamless sleep experience as pure subjective temporality - A commentary on Evan Thompson. In T. Metzinger \& J. M. Windt (Eds.), Open MIND. Frankfurt am Main, Germany: MIND Group.

Windt, J. M., Nielsen, T., \& Thompson, E. (2016). Does consciousness disappear in dreamless sleep? Trends in Cognitive Sciences, 20(12), 871-882. https://doi.org/10.1016/j.tics.2016.09.006

Woods T. J., Windt, J. M., \& Carter, O. (2020). Silence in Shamatha, Transcendental, and Stillness meditation: An evidence synthesis based on expert texts. Frontiers in Psychology, 11, 1-19. https://doi.org/10.3389/fpsyg.2020.01259

Woods T. J., Windt, J. M., \& Carter, O. (2021). The path to contentless experience in meditation: An evidence synthesis based on expert texts. MindRxiv.

Yerbury, R. (2021). "Let's be still”: A school psychologist delivered stillness meditation program for wellbeing. Journal of Psychologists and Counsellors in Schools, 1-11. https://doi.org/10.1017/jgc.2021.12

Zanesco, A. P., King, B. G., Powers, C., De Meo, R., Wineberg, K., MacLean, K. A., \& Saron, C. D. (2019). Modulation of event-related potentials of visual discrimination by meditation training and sustained attention. Journal of Cognitive Neuroscience, 31(8), 1184-1204. https://doi.org/10.1162/jocn_a_01419 